\title{
Vasohibin 2 promotes lymphangiogenesis of lung squamous cell carcinoma through snail-dependent vascular endothelial growth factor-D (VEGF-D) signaling pathway
}

\author{
Pengpeng Liu ${ }^{1,2 \#}$, Rui Zhang ${ }^{1,2 \#}$, Lei Han ${ }^{1,2}$, Xiao Zhang ${ }^{1,2}$, Yingnan Ye ${ }^{1,2}$, Wenwen Yu ${ }^{2,3}$, Xiubao Ren ${ }^{2,3}$, \\ Weijia Zhang ${ }^{4}$, Jinpu Yu ${ }^{1,2,3}$ \\ ${ }^{1}$ Cancer Molecular Diagnostics Core, Tianjin Medical University Cancer Institute \& Hospital, National Clinical Research Center of Caner, Key \\ Laboratory of Cancer Prevention and Therapy, Key Laboratory of Cancer Immunology and Biotherapy, Tianjin, China; ${ }^{2}$ Tianjin's Clinical Research \\ Center for Cancer, Tianjin, China; ${ }^{3}$ Department of Immunology, Tianjin Medical University Cancer Institute \& Hospital, National Clinical \\ Research Center of Caner, Key Laboratory of Cancer Prevention and Therapy, Key Laboratory of Cancer Immunology and Biotherapy, Tianjin, \\ China; ${ }^{4}$ Department of Medicine, Icahn School of Medicine at Mount Sinai, New York, NY, USA \\ Contributions: (I) Conception and design: J Yu; (II) Administrative support: J Yu; (III) Provision of materials or patients: P Liu, Y Ye, X Ren; (IV) \\ Collection and assembly of data: L Han; (V) Data analysis and interpretation: P Liu, R Zhang, X Zhang; (VI) Manuscript writing: All authors; (VII) \\ Final approval of manuscript: All authors. \\ \#These authors contributed equally to this work. \\ Correspondence to: Jinpu Yu, PhD. Cancer Molecular Diagnostics Core, Tianjin Medical University Cancer Institute \& Hospital, National Clinical \\ Research Center of Caner, Key Laboratory of Cancer Prevention and Therapy, Key Laboratory of Cancer Immunology and Biotherapy, Tianjin \\ 300060, China. Email: jyu@tmu.edu.cn.
}

Background: Tumor lymphatic metastasis is mostly dependent on lymphangiogenesis, which was less studied compared to angiogenesis and the molecular mechanisms involved remained unclear.

Methods: We analyzed the mRNA expression profiles of 937 primary lung squamous cell carcinoma (LUSC) samples from The Cancer Genome Atlas (TCGA) and Gene Expression Omnibus (GEO) databases to explore the genes related to lymphatic metastasis in LUSC. We focused on vasohibin 2 (VASH2) and investigated its biological functions in LUSC proliferation, apoptosis, migration, invasion, as well as lymphangiogenesis capacity by forced over-expressing VASH2 in LUSC cell line H520 in vitro and in vivo. We also evaluated the anti-tumor efficacy of specific anti-VASH2 antibody in LUSC xenograft-bearing mice models.

Results: Vasohibin2 (VASH2) was filtered out as a significant predictive factor of poor prognosis and lymphatic metastasis in LUSC patients both in public datasets and an independent Chinese LUSC cohort. VASH2 promoted the proliferation and invasion of LUSC cells in vitro and vivo. Forced over-expression of VASH2 in LUSC cells promoted the amplification and tube formation capacity of human umbilical vein endothelial cells (HUVECs) and human lymphatic endothelial cells (HLECs) via up-regulating vascular endothelial growth factor-D (VEGF-D), which could be reversed via Snail inhibition. Furthermore, blocking VASH2/VEGF-D signaling using specific antibodies dramatically inhibited tumor growth in mice by interfering with the proliferation of cancer cells and lymphangiogenesis in tumor tissues.

Conclusions: In conclusion, VASH2 facilitated lymphangiogenesis and tumor growth in a Snail-dependent manner and might serve as a novel biomarker for early diagnosis and prognosis prediction, as well as a potential therapeutic target in LUSC.

Keywords: Vasohibin 2 (VASH2); lymphangiogenesis; lung squamous cell carcinoma (LUSC); Snail; vascular endothelial growth factor-D (VEGF-D)

Submitted Aug 23, 2021. Accepted for publication Jan 05, 2022.

doi: $10.21037 / \mathrm{atm}-21-4865$

View this article at: https://dx.doi.org/10.21037/atm-21-4865 


\section{Introduction}

Lung cancer is one of the most common human malignancies. With a high worldwide incidence and mortality (1), the 5-year survival rate is about $18.1 \%(2,3)$, mainly due to the aggressive invasion and rapid progression of the disease (1). Non-small cell lung cancer (NSCLC) accounts for the majority (>85\%) of all lung cancers, among which lung squamous cell carcinoma (LUSC) accounts for about $30 \%$ of cases. However, LUSC gains little benefit from targeted therapies compared to lung adenocarcinoma (LUAD) (4), and there is an urgent need to uncover the molecular mechanisms involved in its aggressive invasion and metastasis to develop novel therapeutic strategies with high efficiency for LUSC.

Invasion and metastasis are a complex dynamic process involving multiple factors, which mainly occur through blood vessels and lymphatic vessels. In LUSC, some studies have suggested lymphangiogenesis could enhance the affinity of tumor cells to lymphatic vessels, further promoting invasion and metastasis through lymphatic vessels (5), although the mechanism in LUSC development and progression are unclear. Considering LUSC metastasis may stem from invasion into lymph nodes through lymphatic vessels $(6,7)$, specific interdiction of lymphangiogenesis would provide more efficient inhibition on LUSC invasion compared to routine anti-angiogenesis treatment. Therefore, identifying the key biomarkers regulating the process of lymphangiogenesis in LUSC will throw light on the development of anti-cancer therapeutic strategies for this disease (8-10).

In previous study, we analyzed the mRNA expression profiles of 937 primary LUSC samples from the Gene Expression Omnibus (GEO) and The Cancer Genome Atlas (TCGA) databases and filtered out vasohibin 2 (VASH2) as one of the clinically beneficial predictable biomarkers associated with poor prognosis in LUSC. The full-length human VASH2 is composed of 355 amino acid residues (11), and the gene is located on chromosome 1q32.3. While initially reported to be expressed in endothelial cells, VASH2 is mainly expressed in monocytes (MNCs) which are mobilized from bone marrow and infiltrate into the front of germination (12).

VASH2 has been demonstrated to be an angiogenic factor in a variety of tumors, including liver, gastric, breast, and ovarian cancer (13-15), and plays an important role in tumor development (16). However, there are no studies on its expression and function in lung cancer, especially in LUSC. It has been reported that exogenous VASH2 significantly promoted tumor growth and increased microvessel density and hemoglobin concentration (17), while tumor angiogenesis was significantly inhibited in VASH2 knockout mice (18). Furthermore, VASH2 was reported to trigger epithelial-mesenchymal transition (EMT), up-regulate chemotherapeutic resistance, and increase the proportion of cancer stem like cells $(19,20)$ which can generate cellular traits associated with more aggressive malignancy with higher motility and invasiveness by imparting the trait of self-renewal to cancer cells. However, whether VASH2 promoted invasion and metastasis of lung cancer is related to angiogenesis or EMT has not been disclosed.

In this study, we explored the clinical significance of VASH2 in LUSC and potential molecular mechanisms involved in its promotion of the development and progression of LUSC. We demonstrated that a high level of VASH2 was significantly associated with poor prognosis and promoted lymphatic metastasis in patients with LUSC. It was confirmed from cell experiments and animal models that overexpression of VASH2 promoted angiogenesis and lymphangiogenesis, and accelerated the invasion and metastasis of tumor cells by stimulating EMT. The expression of VASH2 could significantly increase the production of Snail and vascular endothelial growth factor-D (VEGF-D) in LUSC cells, and blocking the VASH2/VEGF-D signaling pathway could significantly inhibit the growth of tumor and the formation of lymphatics. In summary, we not only revealed VASH2 as a marker of LUSC, but also proposed new molecular mechanisms of lymphatic metastasis, which provide potential molecular diagnosis and targeted treatment strategies for patients with LUSC.

We present the following article in accordance with the ARRIVE reporting checklist (available at https://atm. amegroups.com/article/view/10.21037/atm-21-4865/rc).

\section{Methods}

\section{Reagents and antibodies}

RPMI1640 (C11875500BT), DMEM/F12 (11330032), fetal bovine serum (10099141), Trypsin (25200072), and antibioticAntimycotic (15240062) were purchased from Gibco BRL (Grand Island, NY, USA). A fluorescein isothiocyanate (FITC) BrdU flow kit (559619), Annexin-V-FITC Apoptosis Detection kit (556547), and Matrigel (356230) were purchased from BD Biosciences (San Jose, CA, USA), and TRIzol (15596026) was purchased from Invitrogen (Grand 
Island, NY, USA). An ELISA kit to detect the secretion of VEGF-D (ELH-VEGFD-001) was purchased from RayBiotech (Norcross, GA, USA), and an ELISA kit to detect secretion of VASH2 (ab155288) was purchased from Abcam (Cambridge, UK). DMSO (D2650) was purchased from Sigma (St. Louis, MO, USA), and Oligo-(dT)15 primer, 10-mM dNTP, RNase inhibitor, and an SYBR Premix Ex $\mathrm{Taq}^{\mathrm{TM}}$ kit (RR820A) were purchased from Takara (Tokyo, Japan). In the flow cytometry assay, all fluoresce-labeled antibodies were purchased from Biolegend (San Diego, CA, USA), including phycoerythrin (PE) anti-human podoplanin lymphatic endothelial cell surface markers, and PE-IgG1. In immunohistochemistry, all antibodies were purchased from Bioss (Beijing, China), and biotinylated secondary goat antimouse or rabbit IgG antibody were purchased from Santa Cruz (Dallas, TX, USA).

\section{Mice}

Female BALB/c mice between 6-8 weeks old were purchased from Beijing SPF Biotechnology Co., Ltd. and maintained at the SPF animal laboratory of Tianjin Medical University Cancer Institute and Hospital (TJMUCH). To establish a LUAD mouse model, mouse LUAD cells $\mathrm{H} 520^{\mathrm{CTRL}}$ and $\mathrm{H} 520^{\mathrm{OV}-\mathrm{VASH} 2}\left(1 \times 10^{6}\right.$ cells in $100 \mu \mathrm{L}$ PBS $)$ were injected into the mammary fat pads to induce tumor formation (1). All procedures that involved mice were approved by the Ethics Committee for Animal Experiments at the TJMUCH (No. NSFC-AE-2020101), in compliance with the Guide for the Care and Use of Laboratory Animals, 8th edition (21). A protocol was prepared before the study without registration.

\section{Cell lines}

Human LUAD cell line H520 was obtained from the Chinese Academy of Medical Sciences tumor cell libraries.

\section{Cell line culture}

The human LUSC cell line H520 was cultured in RPMI 1640 complete medium containing $10 \%$ fetal bovine serum at $37{ }^{\circ} \mathrm{C}$, and in $5 \% \mathrm{CO}_{2}$. By transfecting wildtype $\mathrm{H} 520$ cells (H520 ${ }^{\mathrm{CTRL}}$ ) with VASH2-specific short hairpin RNA (shRNA) lentiviral vectors, H520 ${ }^{\text {OV-VASH2 }}$ cells were established as indicated in our previous work. Stably transfected cells were cloned by limiting dilution and validated using RT-PCR and Western blot as also described in our previous work.

\section{Clinical samples}

This study recruited 64 cases of LUSC patients treated with partial lung resection surgery at the Department of Hepatobiliary Oncology of the TJMUCH from November 2004 to November 2006 and included 49 males and 19 females with a median age of 62.7 years. No prior treatments, including chemotherapy or radiotherapy, were conducted before lung resection surgery was performed, and the postoperative follow-up time was 40-65 months. This study was approved by the Ethics Committee of Tianjin Medical University (No. Ek2017055). The study was conducted in accordance with the principles of the Declaration of Helsinki (as revised in 2013), and written informed consent was obtained from the patients. Tissue samples were flash frozen and stored at $80^{\circ} \mathrm{C}$.

\section{Data processing for public datasets}

Public datasets were downloaded from the GEO and TCGA database. We then collected ten studies of LUSC expression profiling with a minimum of 24 LUSC patients from the GEO database for the meta-analysis study, including 41 datasets from GSE50081, 78 from GSE41271, 55 from GSE30219, 24 from GSE19188, 72 from GSE8894, 43 from GSE42127, 53 from GSE3141, 52 from GSE14814, 66 from GSE37745. We also collected 38 datasets from the Tianjin database, and 415 from TCGA. Detailed information for these datasets is listed in Figure S1.

The workflow for the meta-analysis of the discovery set of one Tianjin and ten public LUSC datasets is depicted in Figure S1. Metagenes associated with short survival ( $<5$ years: 5 years was the median survival of 11 cohorts) and long survival ( $>5$ years) were identified by a meta $P$ value of less than 0.05 by combining $\mathrm{P}$ values from 11 datasets and individual $\mathrm{P}$ values $<0.05$ in at least 4 out of 11 datasets. Metagenes were then subjected to Gene Ontology (GO) and canonical pathway enrichment with multiple pathways databases (KEGG, Reactome, PID, Wiki Pathways, Biocarta, and Panther).

\section{Immunobistochemistry}

All samples were heated for $0.5 \mathrm{~h}$ at $56^{\circ} \mathrm{C}$, deparaffinized in xylene, and rehydrated through graded alcohol. Antigens were retrieved by heating in citrate buffer $(\mathrm{pH}$ 6.0) for 
$20 \mathrm{~min}$, and endogenous peroxidase activity was quenched in a bath of methanol and hydrogen peroxide for $30 \mathrm{~min}$. Samples were then incubated overnight at $4{ }^{\circ} \mathrm{C}$ with mouse antibody and a biotinylated secondary goat anti-mouse or rabbit IgG antibody labeled with streptavidin-horseradish peroxidase (HRP) using a DAB staining kit according to the manufacturer's instructions. Five representative highpower fields (400x magnification) were selected for each tissue section for histological evaluation. For each protein, two parameters, namely, the positive rate (PR) and staining intensity (SI), were used to describe the expression based on the extent and intensity of the positively stained cells in the samples. PR denoted the percentage of positively stained cells in cancer tissues: $\leq 15 \%$, negative (scored as 0 ); $16-50 \%$, positive at low frequency (scored as 1); $51-80 \%$, positive at medium frequency (scored as 2 ); and $\geq 80 \%$, positive at high frequency (scored as 3). SI referred to the ranked SI of positively stained cells in LUSC samples, and ranged from 0 to 3 , which corresponded to negative, weakly positive, moderately positive, and strongly positive. The sum represented the final scores of each protein marker in the samples because protein expression was comprehensively evaluated based on both parameters. A final score of $<4$ was defined as low/negative expression and a final score of $\geq 4$ was defined as high expression.

\section{Lentivirus construction}

The vector (pHBLV-CMV-MCS-3FLAG-EF1-ZsGreenT2A-PURO) was digested at $37{ }^{\circ} \mathrm{C}$ and the gel was recovered. Fragments were then recovered by PCR, and the target fragment was connected with the vector and the reaction system $(20 \mu \mathrm{L})$. A $100-\mu \mathrm{L}$ competent cell suspension was taken from a $-70-^{\circ} \mathrm{C}$ refrigerator and thawed at room temperature, then added to a plasmid DNA solution, shaken gently, placed on ice for $30 \mathrm{~min}$, heat shocked in a $42-{ }^{\circ} \mathrm{C}$ water bath for $90 \mathrm{~s}$, then quickly placed on ice to cool for $3-5$ min after heat shock. A 1-mL LB liquid medium (without antibiotics) was added into the tube, then stirred at $37^{\circ} \mathrm{C}$ for $1 \mathrm{~h}$ in a 220-rpm shaker. The bacteria were restored to a normal growth state, and the expressed antibiotic resistance gene encoded by plasmid. After shaking the above bacterial solution, centrifugation was performed to remove a $900-\mu \mathrm{L}$ supernatant, and after the remaining culture medium was sucked and mixed, $100 \mu \mathrm{L}$ was applied to the screening plate containing antibiotics. The plate was placed upside down for $30 \mathrm{~min}$, and after the bacterial solution was completely absorbed by the medium, the plate was inverted and cultured at $37^{\circ} \mathrm{C}$ for $16-24 \mathrm{~h}$. After the transformation, the plates were picked up and shaken for $14 \mathrm{~h}$ at $230 \mathrm{rpm} / \mathrm{min}$ at $37^{\circ} \mathrm{C}$. The positive clones were sent to a sequencing company for sequencing for the construction of VAHS2 and Snail overexpression lentivirus. The synthesized VASH2 shRNA and Snail shRNA were inserted into plvx-U6-CMV-RFP-P2A-BSD and pHBLVU6-MCS-CMV-ZsGreen-PGK-PURO lentiviral vectors respectively. The lentivirus was generated as described above.

\section{Tube formation}

$\mathrm{H} 520^{\mathrm{CTRL}}$ and $\mathrm{H} 520^{\mathrm{OV}-\mathrm{VASH} 2}$ cells were cultured as described above. When the cells reached $80 \%$ confluence, the culture medium was changed to DMEM without fetal bovine serum, and after an additional 48 -h culture, the supernatant was collected as conditioned media (CM) and stored at $20{ }^{\circ} \mathrm{C}$. After being thawed at $4{ }^{\circ} \mathrm{C}$ overnight, the Matrigel was coated in a 96-well plate, then incubated at room temperature for at least $30 \mathrm{~min}$ to gel. Human umbilical vein endothelial cells (HUVECs) or human lymphatic endothelial cells (HLECs) were suspended at a density of $2 \times 10^{5}$ cells $/ \mathrm{mL}$ in the different CMs, and the cell suspensions $(100 \mathrm{~mL})$ were added to each Matrigel coated well. DMEM was substituted for CM for the negative control, and DMEM and VASH2 factor were substituted for CM for the positive control. After $18 \mathrm{~h}$, the formed networks were photographed and analyzed to calculate the formation rate of tubes according to the following equation: formation rate $(\%)=$ cell number ${ }_{\text {Tube quantity }} /$ cell number ${ }_{\text {Total }}$ $\times 100 \%$.

\section{Real-time quantitative PCR (RT-qPCR) analysis for gene expression}

Total RNA was exacted using the TRIzol kit according to the manufacturer's protocol. Complementary DNA was synthesized using equivalent amounts of total RNA $(1 \mu \mathrm{g})$ in a $20-\mu \mathrm{L}$ reverse transcriptase reaction mixture and detected using SYBR Premix $\mathrm{Ex}^{\mathrm{Taq}^{\mathrm{TM}}}{ }^{\text {in a }} 7500$ RealTime PCR System (Applied Biosystems, Foster City, CA, USA). The primers were synthesized from Santa Cruz (Dallas, TX, USA) and their sequences are shown in Table S1. All experiments were performed in triplicate and were calculated for $\Delta \mathrm{CT}$. $\Delta \mathrm{CT}=\mathrm{CT}_{\text {target gene }}-\mathrm{CT}_{\text {reference gene, }}$ and the relative expression quantity of mRNA is 
$2^{-\triangle C T}$. While most of the PCR primer sequences used in this study were referenced from previous studies (22-33), those of eight EMT-related genes (Zeb1, Zeb2, Twist1, Snail, Slug, $\beta$-catenin, $N$-cadherin, and E-cadherin) and VEGF family genes (VEGF- $A, V E G F-C$, and $V E G F-D)$, were designed by ourselves and validated in our previous work.

\section{Enzyme-linked immunosorbent assay (ELISA)}

Cells $\left(4 \times 10^{5}\right)$ were seeded into 6 -well plates and the culture supernatants of $\mathrm{H} 520^{\mathrm{CTRL}}$ and $\mathrm{H} 520^{\mathrm{OV}-\mathrm{VASH} 2}$ cells were collected after $48 \mathrm{~h}$ to determine the VASH2 and VEGF-D levels using the VASH2/VEGF-D ELISA kit.

\section{Western blot analysis}

Cells were harvested and washed twice with PBS $(\mathrm{pH}$ 7.4, $0.15 \mathrm{M}$ ), and total protein was extracted by RIPA buffer (Beyotime, Shanghai, China). Approximately $30 \mu \mathrm{g}$ of total protein was subjected to SDS-PAGE and transferred to PVDF membranes, which were then blocked with $5 \%$ skim milk in TBST and incubated with the primary antibody $(1: 1,000)$ in TBST containing $5 \%$ BSA overnight at $4{ }^{\circ} \mathrm{C}$. The membranes were washed twice with TBST and incubated with HRP-conjugated secondary antibody (1:4,000; Santa Cruz, Dallas, TX, USA) at room temperature for $2 \mathrm{~h}$, exposed using an enhanced chemiluminescence reagent (Chemicon International, USA), then reprobed with anti- $\beta$-actin antibody (Santa Cruz, Dallas, TX, USA) in 1:2,000 dilutions to confirm equal protein loading. The antibodies to detect VASH2, VEGF-D, Snail, and actin were purchased from Cell Signaling Technology (MA, USA).

\section{Cell counting kit-8 (CCK-8) assay}

Cells $\left(8 \times 10^{3}\right)$ were seeded into 96-well plates, and CCK8 solution $(10 \mu \mathrm{L}$; Dojindo Molecular Technologies, Inc., Rockville, MD, USA) was added to each well for different time periods $(2,24,72$, and $96 \mathrm{~h})$ and incubated for $2 \mathrm{~h}$ at $37^{\circ} \mathrm{C}$. Cell viability was represented by the absorbance measured at $450 \mathrm{~nm}$.

\section{Cell apoptosis analysis}

Apoptosis in $\mathrm{H} 520^{\mathrm{CTRL}}$ and $\mathrm{H} 520^{\mathrm{OV}-\mathrm{VASH} 2}$ cells was measured using an Annexin-V-FITC detection kit. After $12 \mathrm{~h}$ of starvation treatment, cells were washed with PBS and resuspended in $1 \times$ binding buffer at a concentration of $1 \times 10^{6}$ cells $/ \mathrm{mL}$. Subsequently, $5 \mu \mathrm{L}$ of Annexin- $\mathrm{V}$ and $10 \mu \mathrm{L}$ of propidium iodide (PI) were added to $100 \mu \mathrm{L}$ of the cell suspension, and the mixture was incubated for $15 \mathrm{~min}$ in the dark. The analyses were performed using a flow cytometry. As the growth factors were dissolved in DMSO for the cell culture experiment, DMSO was added into the medium and diluted at a final concentration of $5 \mu \mathrm{g} / \mathrm{mL}$, serving as a negative control to eliminate disturbance of the solvent. The experiments were repeated at least three times.

\section{Wound bealing assay}

Cells were seeded into 6-well plates for $24 \mathrm{~h}$ to reach $80-90 \%$ confluence. The cell monolayer was wounded in a straight line with a $10-\mu \mathrm{L}$ pipette tip to create a "wound", then cell debris was removed by PBS and the wounded cells were cultured with fresh medium. Images were taken at 0 , 24 , and $48 \mathrm{~h}$ later to measure the distance of the wound. The cell migration rate $=($ the distance of the wound at $0 \mathrm{~h}$ - the distance of the wound at 24 or $48 \mathrm{~h}$ )/the distance of the wound at $0 \mathrm{~h} \times 100 \%$. The experiments were repeated at least three times.

\section{Transwell invasion assay}

Matrigel and Transwell were used to carry out lung cancer cell invasion assays to build invading chambers for separating high invasive and low invasive cells. Cells were seeded at a density of $1 \times 10^{5}$ cells in the Matrigel and $100-\mu \mathrm{L}$ serum-free RPMI-1640 in the 24-well plate Transwell system with an 8 - $\mu \mathrm{m}$ pore size polycarbonate filter membrane (Corning, NY, USA). The lower chambers contained $10 \%$ FBS containing medium. The cells were incubated for $48 \mathrm{~h}$, then those on the lower surface of the membrane were fixed with methanol and stained with $1 \%$ toluidine blue. The stained membranes were photographed through the microscope and invading cells were counted. The experiments were repeated at least three times.

\section{In vivo tumorigenicity study}

After the mice construction, we monitored tumor growth at 3 -day intervals. There were 5 mice in each group $(\mathrm{N}=5$ in each group). Each experiment was performed in triplicate. For each animal, three different investigators were involved as follows: a first investigator administered different cells 
into the flanks of mice via subcutaneous injection based on the randomization criteria. This investigator was the only person aware of the construction group allocation. A second investigator was responsible for monitoring tumor growth at 3-day intervals. Finally, when the tumor size reached $1 \mathrm{~cm}^{3}$, a third investigator sacrificed the mice and collected all the tumors from mice. $\mathrm{H} 520^{\mathrm{CTRL}}$ and $\mathrm{H} 520^{\mathrm{OV}-\mathrm{VASH} 2}$ cells were collected, and an equal number of $1 \times 10^{6}$ cells in $100 \mu \mathrm{L}$ of PBS were mixed with Matrigel, respectively. The mixed cells were then injected subcutaneously into both flanks of the BALB/c mouse, and the tumor sizes were monitored every 3 days. Each group contained five mice, and the experiments were repeated at least three times. The tumor volume $(\mathrm{V})$ was calculated by the formula: $\mathrm{V}=3.14 \times \mathrm{L} \times \mathrm{W} \times \mathrm{H} / 6$ (L: length, $\mathrm{W}:$ width, $\mathrm{H}$ : height).

Once palpable tumors were formed (in $\sim 7-10$ days), treatment cycles were initiated, with the mice first anesthetized by intraperitoneal injection of $100 \mathrm{mg} / \mathrm{kg}$ antiVEGF-D and $10 \mathrm{mg} / \mathrm{kg}$ anti-VASH2. Treatment involved the mice being randomly divided into three groups, control, anti-VEGF-D, and anti-VASH2, with each group containing five mice. The control group of mice were also subjected to $1 \times$ PBS injections for five consecutive days. After completion of the treatment cycle the mice were sacrificed, the tumors excised, tumor volume measured using a caliper, and volumes calculated as previously mentioned. Tumors were then fixed and processed for immunohistochemistry.

\section{Flow cytometry}

The concentration of antibodies used for staining and the time of co-incubation were calculated following the manufacturer's instruction, with $\mathrm{PE}$ anti-human podoplanin antibody used at a concentration of $12.5 \mu \mathrm{g} / \mathrm{mL}$. Before being washed and fixed with $4 \%$ paraformaldehyde, $1 \times 10^{5}$ cells were resuspended in $100 \mu \mathrm{L} \mathrm{PBS}$, and as all protein markers are membrane proteins, no cells were permeabilized. Samples were analyzed by a BD FACS Aria flow cytometer (BD Biosciences).

\section{Statistical analyses}

Data were analyzed using SPSS 17.0. Quantitative data are presented as mean \pm standard deviation and Student's $t$-test was used to analyze statistical comparisons between two groups. For more than two groups, one-factor ANOVA assay was used to evaluate the difference among all groups, followed by the least significant difference (LSD) method to compare the difference between each of the two groups. Statistical significance was set at $\mathrm{P}<0.05$.

\section{Results}

\section{High expression of VASH 2 correlated with worse prognosis and more lymphatic metastasis in LUSC patients}

We collected and analyzed the global gene expression profile of 937 primary LUSC tissue samples from 11 databases based on the disparity in clinical outcomes. Patients with a survival time more than 40 months were designated as a good prognosis group, and those with a survival time less than 40 months as a poor prognosis group, and we identified 12 highly differentially expressed genes which significantly correlated with a poor prognosis (Figure S1). LUSC tissue samples were collected from TJMUCH to validate the correlation between the 12 identified genes and overall survival (OS) in 20 cases. Immunohistochemical (IHC) staining results and Kaplan-Meier survival analysis indicated that patients with a high expression of VASH2 and IL-33 had a significantly worse prognosis (VASH2: $25.13 \pm 11.57$ vs. $52.42 \pm 30.65$ months, $\mathrm{P}=0.023$; IL-33: $30.55 \pm 8.39$ vs. $50.45 \pm 21.18$ months, $\mathrm{P}=0.032$; Figure $1 A$ ). Among them, overexpression of VASH2 was significantly correlated with poor prognosis in 4 of 11 databases, indicating VASH2 was a novel prognostic factor of LUSC whose high expression was significantly correlated with comparably shorter OS in different databases (Figure 1B). TCGA data findings also implied that VASH2, previously reported to be associated with angiogenesis, was significantly up-regulated in LUSC cases suffering from shorter OS and might be a potential prognosis predictive biomarker for it.

To validate the correlation between VASH2 and clinical outcomes in LUSC, we collected another independent cohort composed of 64 LUSC samples from TJMUCH. The mRNA level of VASH2 in LUSC samples was detected using RT-qPCR assay and showed that low VASH2 expression was mainly found in patients surviving more than 40 months, while the level of VASH2 mRNA in the good prognosis group was much lower than that of the poor prognosis group $(10.68 \pm 1.13$ vs. $10.14 \pm 0.96, \mathrm{P}=0.01$, Figure $1 C$ ). In addition, we compared the level of VASH2 protein in the corresponding LUSC paraffin specimens using IHC analysis and found that it was predominately higher in patients with short OS compared to that seen in patients with long OS $(63.82 \% \pm 5.18 \%$ vs. $20.88 \% \pm 3.74 \%$, 

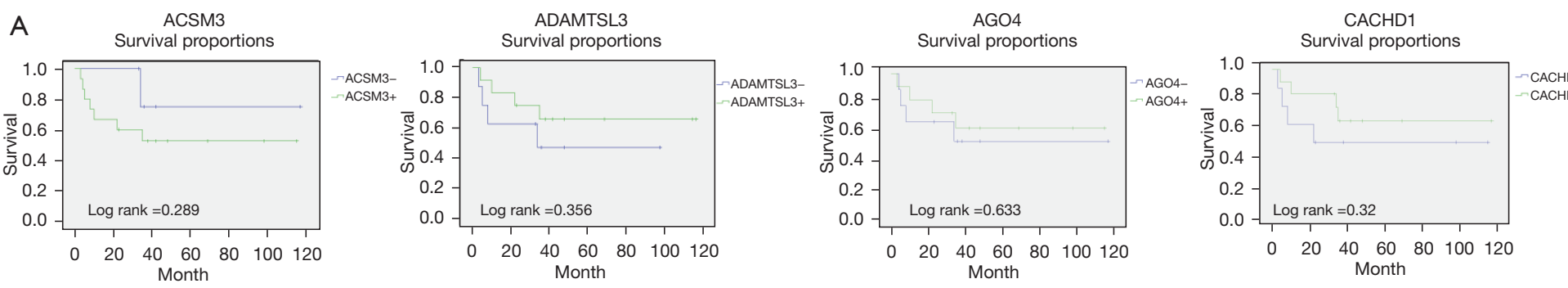

Survival proportions
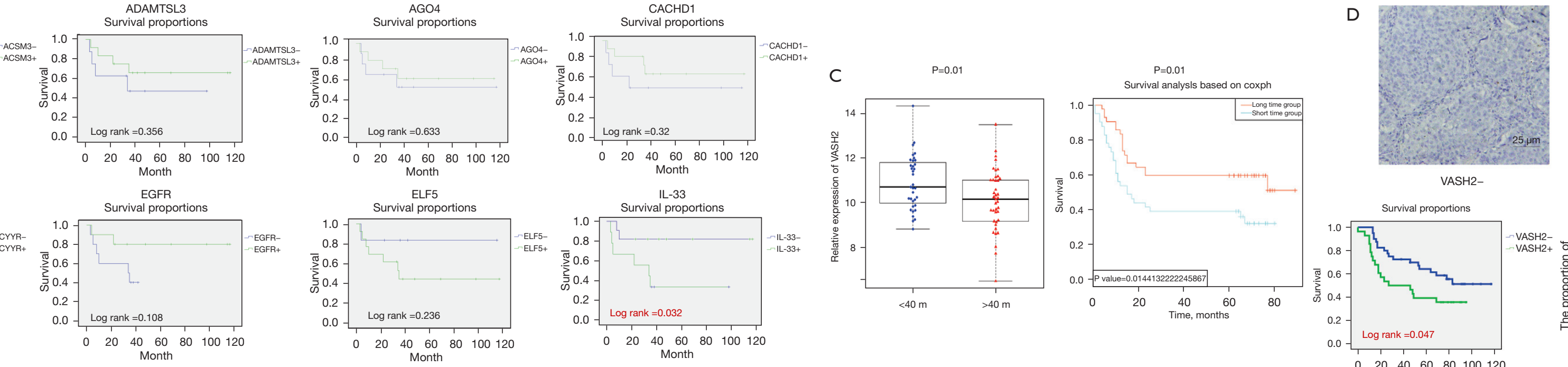

VASH2-

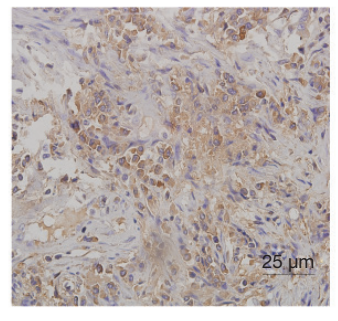

VASH $2+$
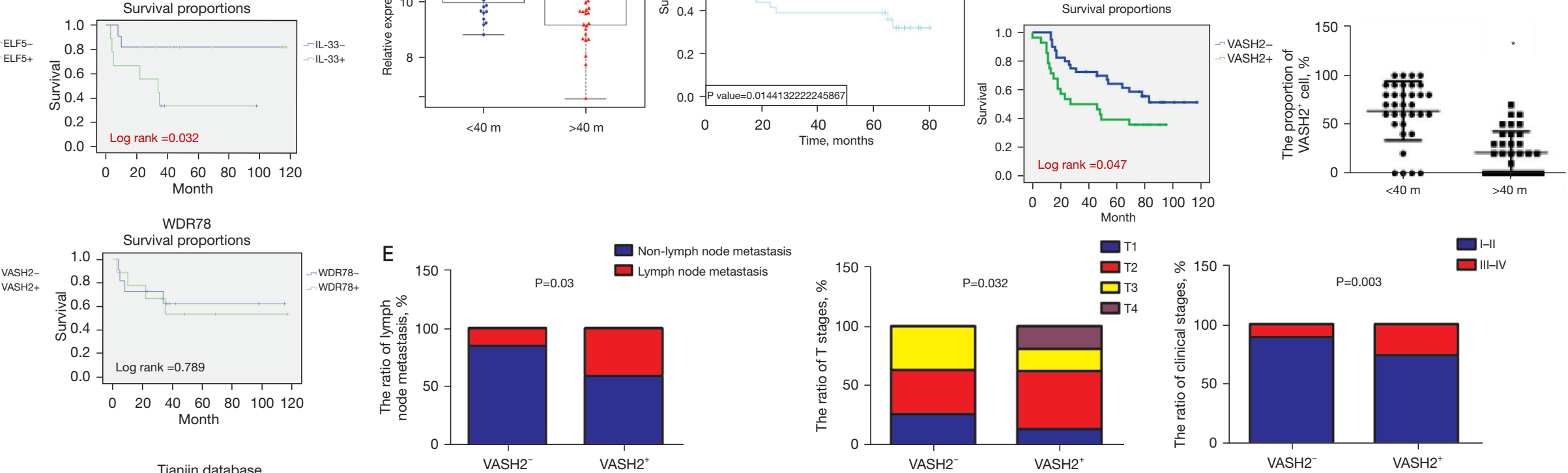

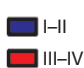
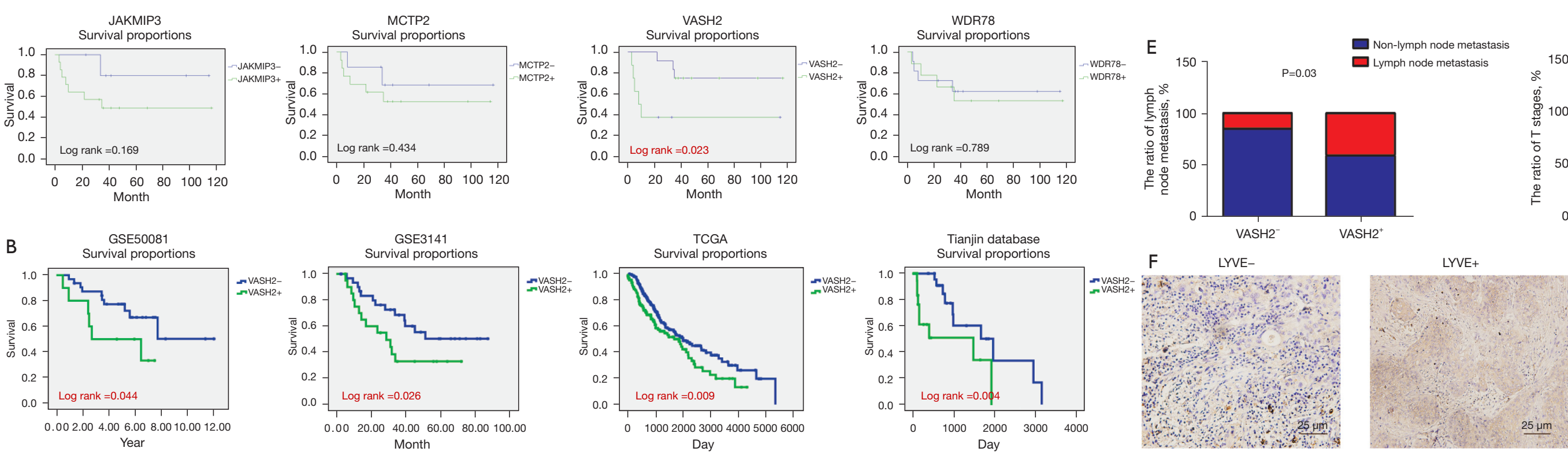

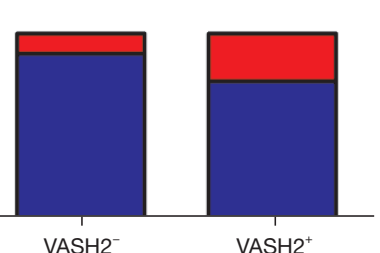

Survival proportions

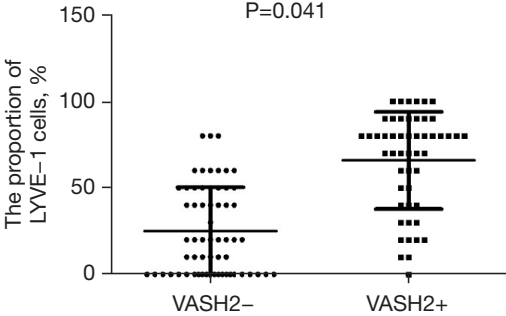

Figure 1 High expression of VASH2 correlated with worse prognosis and more lymphatic metastasis in LUSC patients. (A) LUSC tissue samples were collected from the TJMUCH to validate the correlation between the 12 identified genes and overall survival (OS) in 20 cases. (B) Analysis of the global gene expression profiling of 937 primary LUSC tissue samples from 11 databases based on the disparity in clinical outcomes. (C) An independent cohort comprised of 64 LUSC samples was collected from the TJMUCH and was detected using real-time quantitative PCR assay. (D) Comparison of the level of VASH2 protein in the corresponding LUSC paraffin specimens using IHC analysis. (E) Analysis of the association between VASH2 and other clinicopathology. (F) The proportion of LYVE-1 positive cells in lymphatic endothelial cells in tissue samples was detected by immunohistochemistry, and the correlation between VASH2 and lymphatic density and the effect of lymphatic density on the poor prognosis of patients were analyzed. *, $\mathrm{P}<0.05$ between the groups, respectively. IHC, immunohistochemical; LUSC, lung squamous cell carcinoma; TJMUCH, Tianjin Medical University Cancer Institute and Hospital; VASH2, vasohibin 2; LYVE-1, lymphatic vessel endothelial hyaluronic acid receptor-1; OS, overall survival. 
Table 1 Correlation between VASH2 expression and clinicopathological parameters of patients

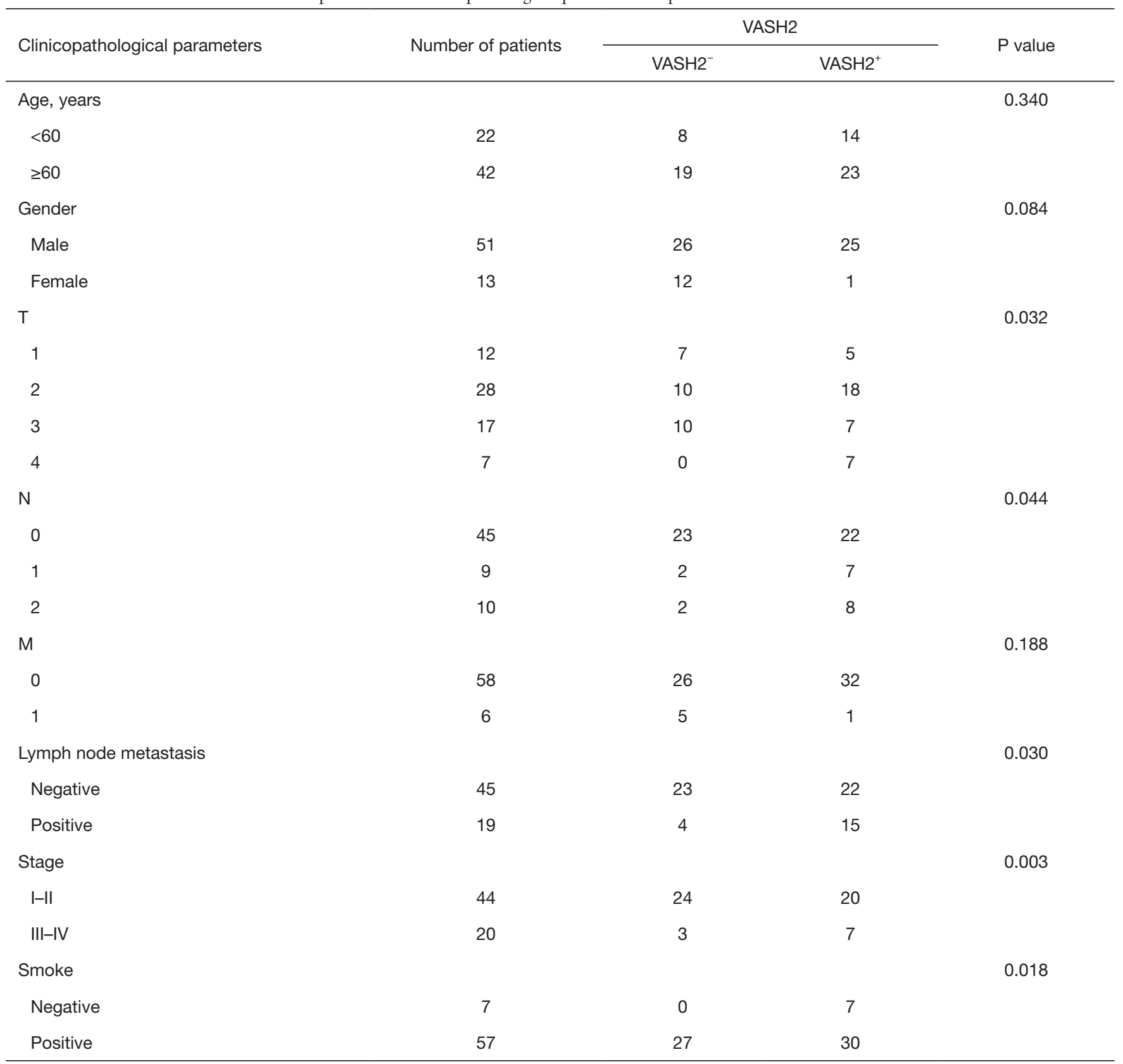

VASH2, vasohibin 2.

$\mathrm{P}=0.01$, Figure $1 D)$. The above results indicated that both the transcription and expression of the VASH2 gene in LUSC were significantly and consistently correlated with poor survival outcomes. Furthermore, we analyzed the association between VASH2 and other clinicopathology and found that its high expression positively corresponded with more lymph node metastasis, larger tumor size, and worse clinical stage (Figure 1E, Table 1).

The protein levels of LYVE-1 in 64 cases of primary LUSC tissues were assessed using IHC staining assay (Figure $1 F$ ). The proportion of LYVE-1 positive cells, referring to lymphoepithelial cells, were higher in VASH2positive LUSC tissues than those in VASH2-negative LUSC tissues $(65.88 \% \pm 3.93 \%$ vs. $25.08 \% \pm 3.24 \%, \mathrm{P}=0.041$, 
Figure $1 F)$. We then compared the correlation between LYVE-1 and OS, and Kaplan-Meier survival analysis indicated that patients with high expression of LYVE1 had a significantly worse prognosis $(50.46 \pm 6.07 \mathrm{vs}$. $84.81 \pm 9.91$ months, $\mathrm{P}=0.031$, Figure $1 F)$. These results indicated VASH2 was a valuable biomarker to predict poor prognosis and lymphatic metastasis in LUSC.

\section{VASH2 accelerated the proliferation and invasion potential of LUSC cells, and promoted the tube-formation capacity of HUVEC and HLEC cells}

Supernatants from cultures of H520 $0^{\text {CTRL }}$ and $\mathrm{H} 520^{\mathrm{OV}-\mathrm{VASH} 2}$ were then collected, and to investigate the underlying biological roles of VASH2 in carcinogenesis and lymphangiogenesis, VASH2 was up-regulated in LUSC cell line NCI-H520 cells by transfecting recombinant lentivirus (Figure S2A). A high level of VASH2 was confirmed in the supernatants of $\mathrm{H} 520^{\mathrm{OV}-\mathrm{VASH} 2}$ compared to that in H5 $20^{\text {CTRL }}$. The level of VASH2 protein in different supernatants was detected by ELISA, and showed H5 $20^{\text {OV-VASH2 }}$ secreted more VASH2 than H520 $0^{\text {CTRL }}$ $(602.75 \pm 73.84$ vs. $196.39 \pm 38.29 \mathrm{pg} / \mathrm{mL}, \mathrm{P}=0.001$, Figure $2 A)$.

We first compared the proliferation and apoptosis of $\mathrm{H} 520^{\mathrm{OV}-\mathrm{VASH} 2}$ and found higher proliferation, but lower apoptosis rates compared to H520 ${ }^{\mathrm{CTRL}}$ (72 h: $3.42 \pm 0.43$ vs. $2.19 \pm 0.36, \mathrm{P}=0.044$, Figure $2 B ; 6.94 \% \pm 1.68 \%$ vs. $15.23 \% \pm 0.98 \%, \mathrm{P}=0.013$, Figure $2 C$ ). The migration and invasion potentials were compared, and the wound closure rates (WCRs) were significantly higher in $\mathrm{H} 520^{\text {OV-VASH2 }}$ cells, and more of these cells migrated across the Matrigel layer after $48 \mathrm{~h}(77.89 \% \pm 7.64 \%$ vs. $56.25 \% \pm 5.47 \%$, $\mathrm{P}=0.016$, Figure $2 D ; 228.67 \pm 16.77$ vs. $174.33 \pm 12.50$, $\mathrm{P}=0.011$, Figure $2 E$ ).

HUVECs and HLECs were then co-cultured with the supernatants from either $\mathrm{H} 520^{\mathrm{OV}-\mathrm{VASH} 2}$ or $\mathrm{H} 520^{\mathrm{CTRL}}$
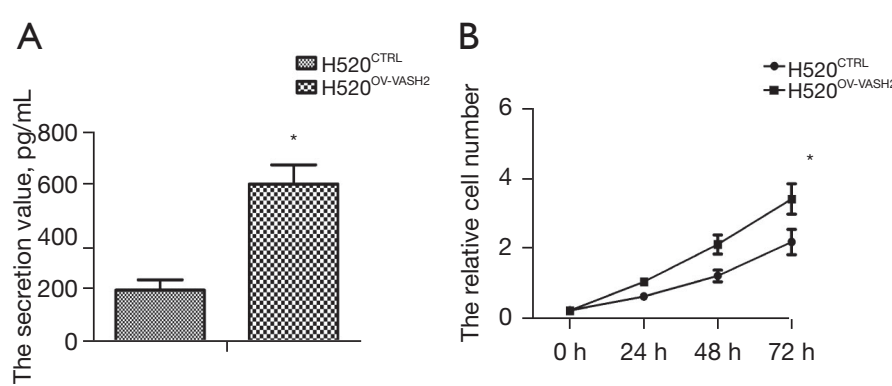

cells, with the HUVECs and HLECs cultured in DMEM medium used as negative controls. The numbers of forming tubes in each group were assessed, and the results showed that when recombinant VASH2 was added to the supernatant, HUVECs and HLECs could form more tubes (HUVEC: $15.38 \% \pm 3.41 \%$ vs. $32.39 \% \pm 8.47 \%, \mathrm{P}=0.032$; HLEC: $20.54 \% \pm 3.17 \%$ vs. $47.64 \% \pm 8.64 \%, \mathrm{P}=0.007$, Figure $2 F, 2 G$ ). The typical tubule formation of HUVEC and HLEC cells was inhibited and reduced by adding specific VASH2 blocking antibody (HUVEC: $32.39 \% \pm 8.47 \%$ vs. $8.65 \% \pm 2.64 \%, \mathrm{P}=0.0098$; HLEC: $47.64 \% \pm 8.64 \%$ vs. $12.19 \% \pm 3.62 \%, \mathrm{P}=0.0028$, Figure $2 F, 2 G$ ). The $\mathrm{H} 520^{\text {OV-VASH2 }}$ supernatant could stimulate both HUVEC and HLECs cells to generate comparable amount of tubes as recombinant VASH2 did in vitro, which was significantly higher than that seen in the H520 ${ }^{\mathrm{CTRL}}$ supernatant did (HUVEC: $39.64 \% \pm 7.31 \%$ vs. $21.39 \% \pm 4.35 \%, \mathrm{P}=0.021$; HLEC: $43.67 \% \pm 7.64 \%$ vs. $14.67 \% \pm 5.37 \%, \mathrm{P}=0.0058$, Figure $2 \mathrm{H}, 2 \mathrm{I})$. However, after adding specific VASH2 blocking antibody, the typical tube formation of HUVEC cells was partly inhibited, while that of HLECs was fully eliminated (HUVEC: $25.36 \% \pm 4.39 \%$ vs. $39.64 \% \pm 7.31 \%$, $\mathrm{P}=0.043$; HLEC: $16.23 \% \pm 8.73 \%$ vs. $43.67 \% \pm 7.64 \%$, $\mathrm{P}=0.015$, Figure $2 \mathrm{H}, 2 \mathrm{I}$ ). These results implied that VASH2 not only effectively promoted proliferation and the invasion potential of LUSC cells, but also significantly enhanced lymphangiogenesis in vitro.

\section{VASH2 facilitated lymphangiogenesis via up-regulating VEGF-D production in LUSC cells}

To define the molecular events regulating VASH2-related lymphangiogenesis, the transcription and expression of lymphangiogenesis-related VEGF family members in $\mathrm{H} 520^{\mathrm{OV}-\mathrm{VASH}}$ cells, including VEGF-A, VEGF-C, and VEGF-D, were measured using qPCR assay. While no

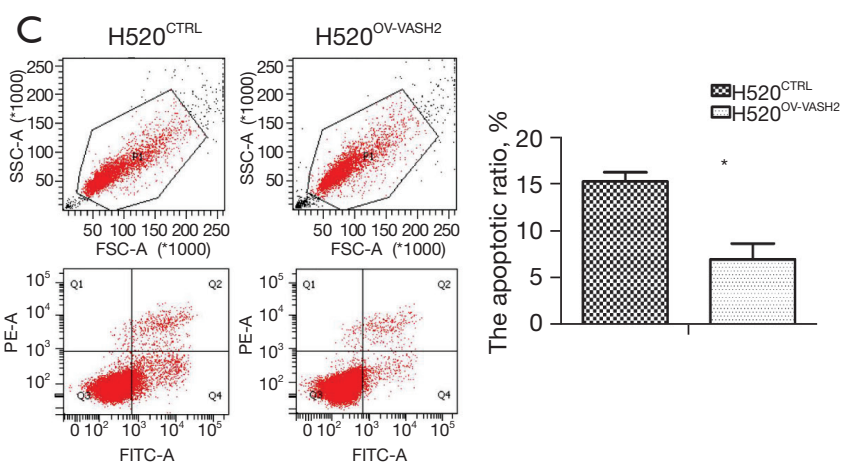



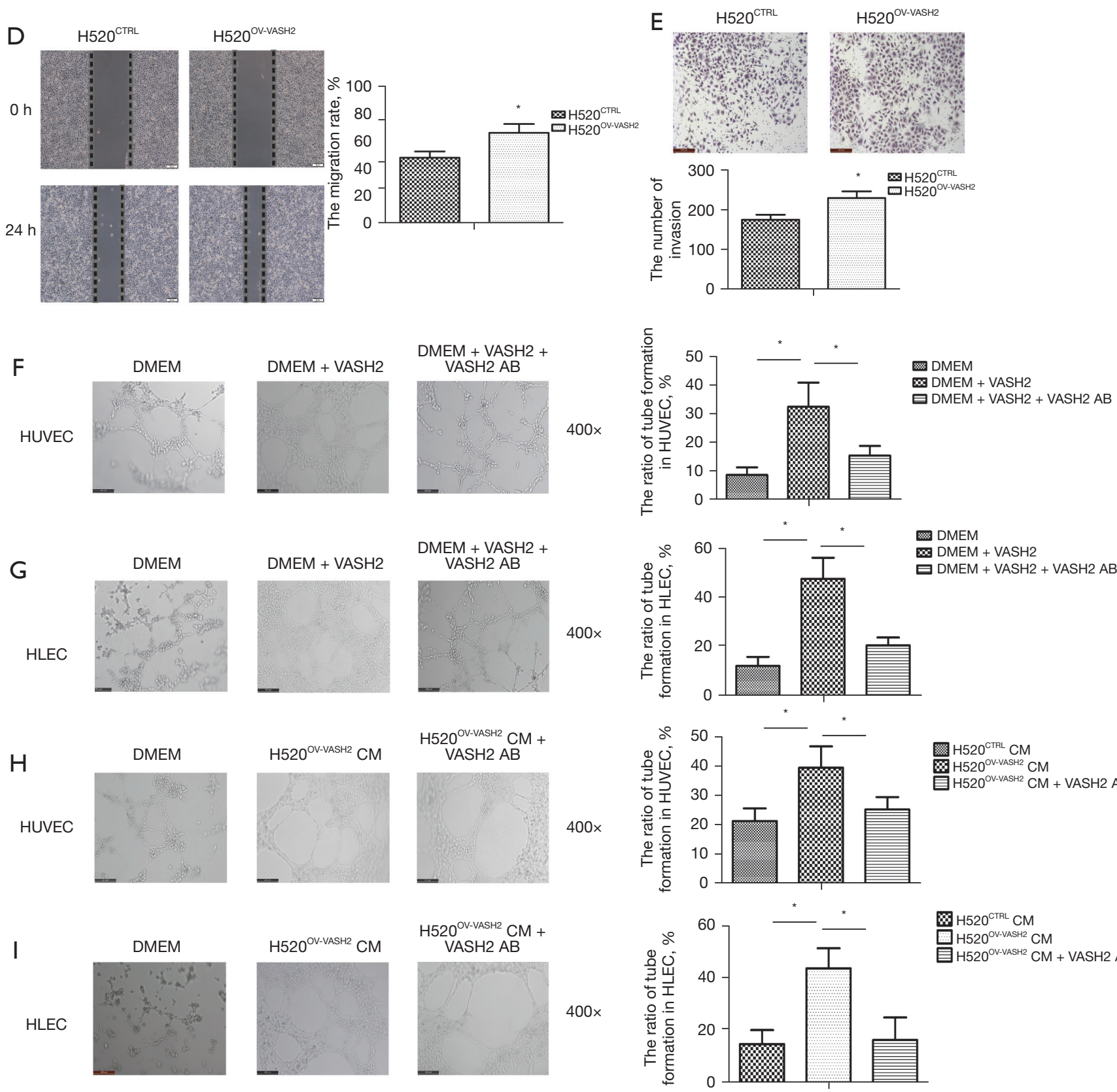

冈 DMEM

DMEM + VASH2

DMEM + VASH2 + VASH2 AB $400 x$

$400 \times$

$400 x$

Figure 2 VASH2 accelerated the proliferation and invasion potential of LUSC cells, and promoted the tube-formation capacity of HUVEC and HLEC cells. (A) A high level of VASH2 was confirmed in the supernatants of H520 ${ }^{\text {OV-VASH2 }}$ compared to that in H520 CTRL detected by ELISA. (B) Comparison of the proliferation of H520 ${ }^{\mathrm{OV}-\mathrm{VASH} 2}$ by CCK-8 assay. (C) Apoptotic H520 ${ }^{\mathrm{CTRL}}$ and H520 ${ }^{\mathrm{OV}-\mathrm{VASH} 2}$ cells were measured using Annexin-V-FITC. (D) The migration and invasion potentials were compared by wound healing assay. Images were taken at 0 , 24, and $48 \mathrm{~h}$ later to measure the wound. (E) Matrigel and Transwell were used to carry out lung cancer cell invasion assays to build invading chambers for separating high invasive and low invasive cells. The stained membranes were photographed through the microscope and invading cells were counted after $48 \mathrm{~h}$ (toluidine blue stain). (F-I) HUVECs and HLECs were co-cultured with the supernatants from either $\mathrm{H} 520^{\mathrm{OV}-\mathrm{VASH} 2}$ or H520 ${ }^{\mathrm{CTRL}}$ cells. The HUVECs and HLECs cultured in DMEM medium were used as negative controls. The numbers of forming tubes in each group were assessed. Scale bar: $200 \mu \mathrm{m} .{ }^{*}, \mathrm{P}<0.05$ between the groups, respectively. HLECs, human lymphatic endothelial cells; HUVECs, human umbilical vein endothelial cells; LUSC, lung squamous cell carcinoma; VASH2, vasohibin 2; ELISA, enzyme-linked immunosorbent assay; CCK-8, cell counting kit-8 assay; CM, conditioned media; FITC, fluorescein isothiocyanate. 

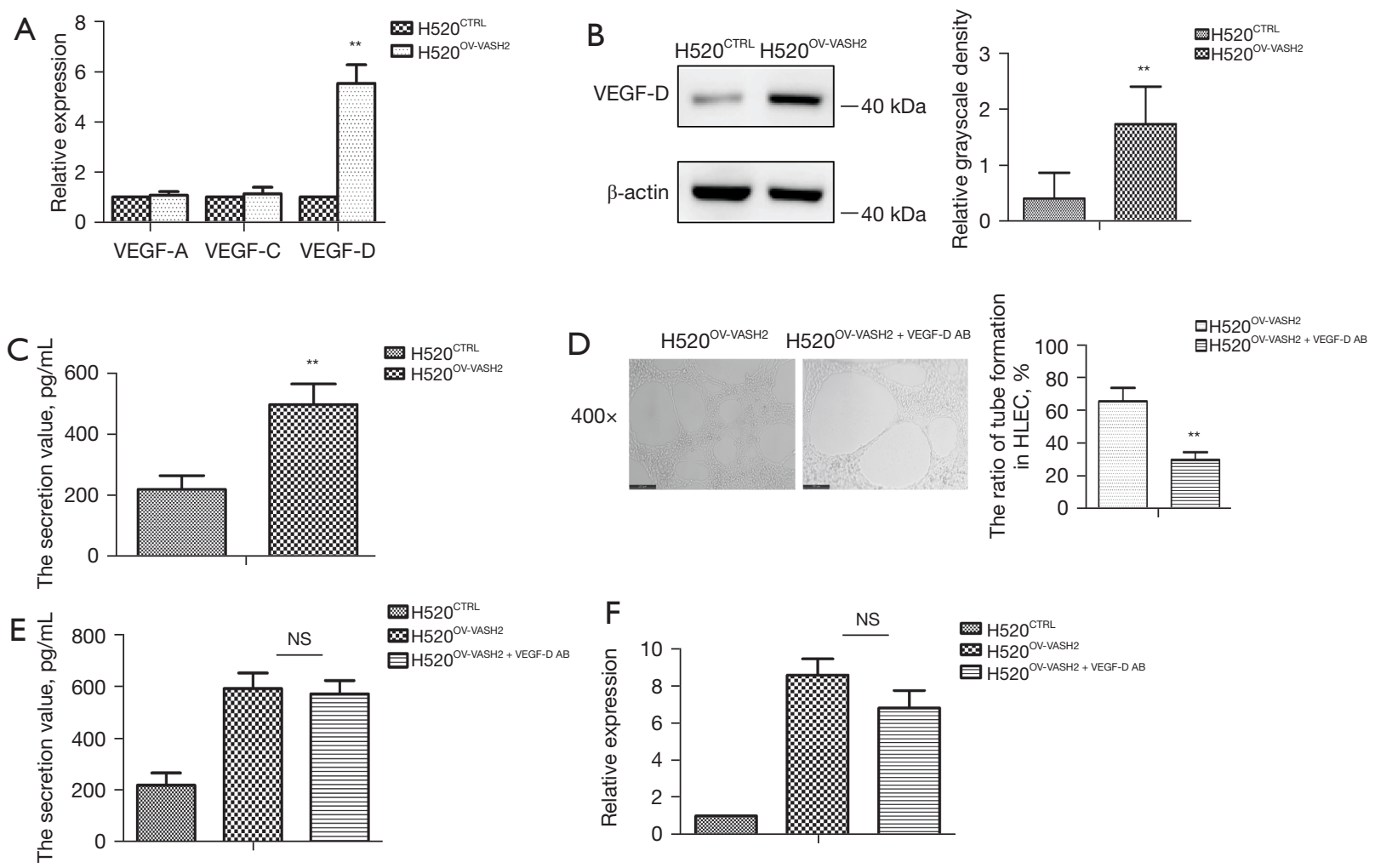

Figure 3 VASH2 facilitated lymphangiogenesis via up-regulating VEGF-D production in LUSC cells. (A) VEGF family members in H520 ${ }^{\text {OV-VASH2 }}$ cells, including VEGF-A, VEGF-C, and VEGF-D, were measured using qPCR assay. (B) The protein level of VEGF-D in $\mathrm{H} 520^{\mathrm{OV}-\mathrm{VASH} 2}$ cells was detected by Western blot analysis. (C) The level of VEGF-D protein in the supernatants of H520 ${ }^{\mathrm{OV}-\mathrm{VASH} 2}$ and H520 ${ }^{\text {CTRL }}$ was compared by ELISA assay. (D) The influence of specific VEGF-D blocking antibody on the tube formation of HLECs cocultured with $\mathrm{H} 520^{\mathrm{OV}-\mathrm{VASH} 2}$ was tested. (E,F) VEGF-D antibody was added to the two groups of cells respectively. The effect of VEGF-D on VASH2 production and release was detected by ELISA and PCR. Scale bar: $200 \mu \mathrm{m}$. ** $\mathrm{P}<0.01$ between the groups, respectively. HLECs, human lymphatic endothelial cells; LUSC, lung squamous cell carcinoma; VASH2, vasohibin 2; VEGF, vascular endothelial growth factor; RT-qPCR, Real-time quantitative PCR; ELISA, Enzyme-linked immunosorbent assay; NS, no significance.

significant difference at the mRNA levels of VEGF-A and VEGF-C was detected between H520 CTRL and $\mathrm{H} 520^{\mathrm{OV}-\mathrm{VASH} 2}$ cells, the mRNA and protein level of VEGF-D in the latter was significantly higher than that in the former $(\mathrm{P}=0.008, \mathrm{P}=0.046$, Figure $3 A, 3 B)$. The level of VEGF-D protein in the supernatants of $\mathrm{H} 520^{\mathrm{OV}-\mathrm{VASH} 2}$ and $\mathrm{H} 520^{\mathrm{CTRL}}$ was then compared by ELISA assay, and showed $\mathrm{H} 520^{\text {OV-VASH2 }}$ secreted more VEGF-D than H520 CTRL $(497.37 \pm 67.51$ vs. $218.54 \pm 45.36 \mathrm{pg} / \mathrm{mL}, \mathrm{P}=0.023$, Figure $3 C$ ). Furthermore, specific VEGF-D blocking antibody could efficiently inhibit the tube formation of HLECs co-cultured with H520 $0^{\mathrm{OV}-\mathrm{VASH} 2}(29.67 \pm 4.67$ vs. $64.48 \pm 8.12, \mathrm{P}=0.003$, Figure $3 D)$. These data implied VASH2 over-expression promoted the production and secretion of VEGF-D in LUSC cells, which might directly facilitate VASH2-indiced lymphangiogenesis in vitro. VEGF-D antibody was added to the two groups of cells respectively, and its effect on VASH2 production and release was detected by ELISA and PCR. The level of VASH2 protein in the supernatants was not different

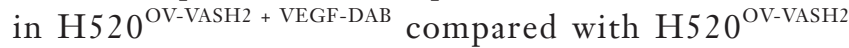
$(563.54 \pm 89.21$ vs. $592.72 \pm 60.34 \mathrm{pg} / \mathrm{mL}, \mathrm{P}=0.24$, Figure $3 E)$, and there was also no difference in mRNA expression $(6.83 \pm 1.64$ vs. $8.61 \pm 1.51, \mathrm{P}=0.24$, Figure $3 F)$.

\section{VASH2 enhanced tumor proliferation and invasion via up- regulating Snail expression in LUSC cells}

The transcription of multiple EMT-related biomarkers was detected using qPCR assay and showed while the 

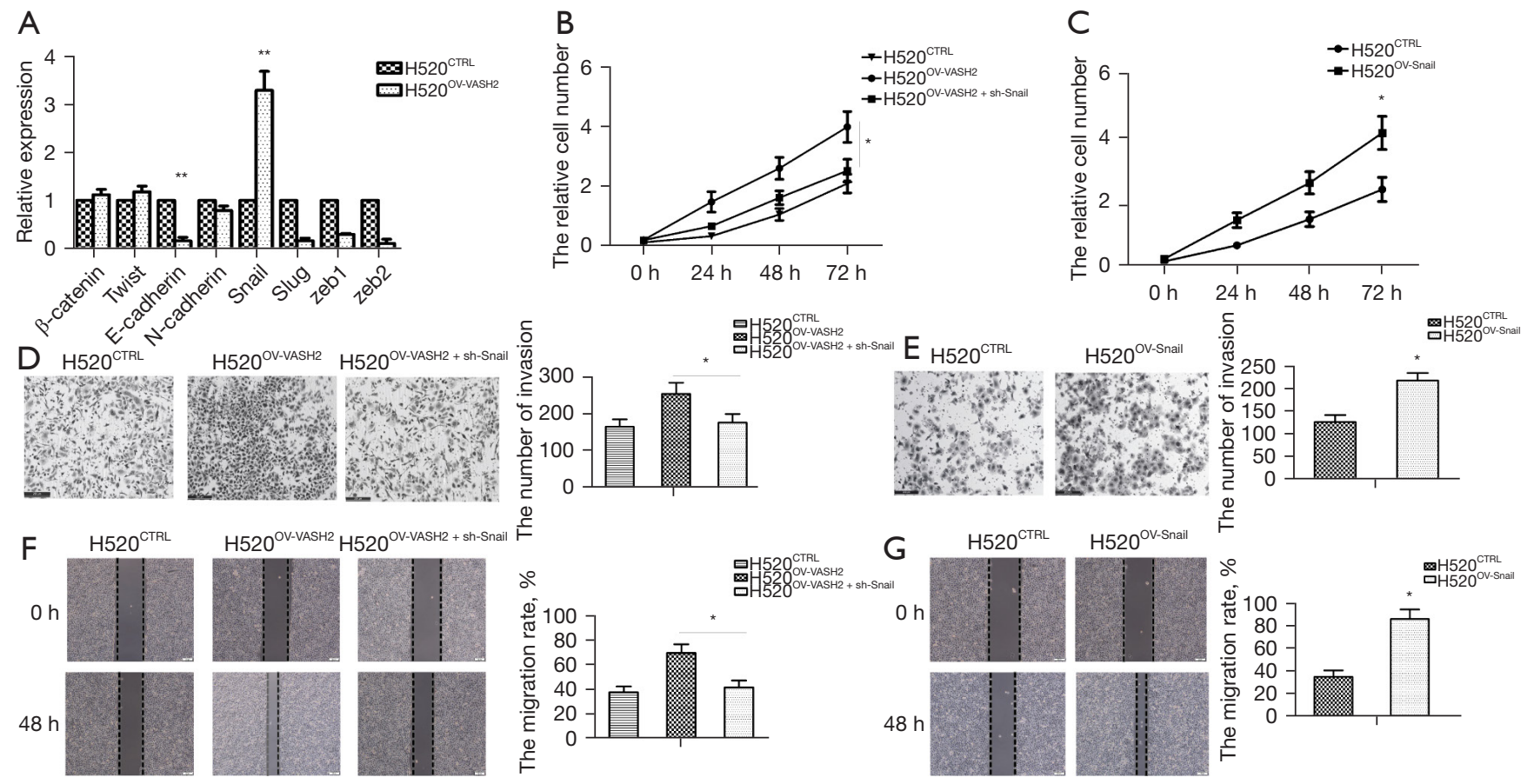

Figure 4 VASH2 enhanced tumor proliferation and invasion via up-regulating Snail expression in LUSC cells. (A) The transcription of multiple EMT-related biomarkers was detected using qPCR assay. (B,C) We compared the proliferation of $\mathrm{H} 520^{\mathrm{CTRL}}$, $\mathrm{H} 520^{\mathrm{OV}-\mathrm{VASH}}$, $\mathrm{H} 520^{\mathrm{OV}-}$ $\mathrm{VASH}_{2}+$ sh-Snail , and H520 ${ }^{\text {OV-Snail }}$ cells using CCK-8 staining assay. (D,E) Cell invasion was compared Transwell assays. (F,G) Cell migration was compared using the wound healing. Scale bar: $200 \mu \mathrm{m} .{ }^{*}, \mathrm{P}<0.05$ and **, $\mathrm{P}<0.01$ between the groups, respectively. LUSC, lung squamous cell carcinoma; VASH2, vasohibin 2; CCK-8, cell counting kit-8 assay; EMT, epithelial mesenchymal transitions.

level of Snail mRNA increased in $\mathrm{H} 520^{\mathrm{OV}-\mathrm{VASH}}$ compared to $\mathrm{H} 520^{\mathrm{CTRL}}$, that of E-cadherin decreased, indicating VASH2 promoted EMT in LUSC cells. However, there was no significant difference in the mRNA levels of the mesenchymal cell biomarkers $\beta$-catenin and $\mathrm{N}$-cadherin, and other EMT-related transcription factors (TFs), such as Zeb family (Zeb1 and Zeb2), Slug, and Twist1 (Figure 4A). These results implied that VASH2 promoted LUSC cell EMT by stimulating Snail transcription.

To further determine if VASH2 up-regulated LUSC cell proliferation and invasion via Snail, we designed a recombinant lentivirus to knock down Snail in H520 OV-VASH2 cells (H520 ${ }^{\mathrm{OV}-\mathrm{VASH} 2}+$ sh-Snail $)$, as well as another recombinant lentivirus to force the over-expression of Snail in wildtype $\mathrm{H} 520$ cells to establish H520 ${ }^{\text {OV-Snail }}$ (Figure S2B,S2C). We compared the proliferation of $\mathrm{H} 520^{\mathrm{CTRL}}$, $\mathrm{H} 520^{\mathrm{OV}-\mathrm{VASH}}$, $\mathrm{H} 520^{\text {OV-VASH2 }+ \text { sh-Snail }}$, and H520 $0^{\text {OV-Snail }}$ cells using the CCK-8 staining assay and found that the proliferation rates were lower in $\mathrm{H} 520^{\mathrm{OV}-\mathrm{VASH} 2}$ + sh-Snail than that in $\mathrm{H} 520^{\mathrm{OV}-V A S H 2}$ (H $520^{\text {OV-VASH2 }+ \text { sh-Snail }}: 2.51 \pm 0.38 ; \mathrm{H} 520^{\mathrm{OV}^{\mathrm{VASH}} 2}$ : $3.97 \pm 0.52$; H520 ${ }^{\mathrm{CTRL}}: 2.07 \pm 0.31, \mathrm{P}=0.022$, Figure $4 B$ ), and the proliferation rates were higher in $\mathrm{H} 520^{\text {OV-Snail }}$ than in H520 ${ }^{\text {CTRL }}(4.14 \pm 0.52$ vs. $2.36 \pm 0.38, \mathrm{P}=0.031$, Figure $4 C$ ). Cell migration and invasion were compared using the wound healing and Transwell assays and showed that less $\mathrm{H} 520^{\mathrm{OV}-\mathrm{VASH}}+$ sh-Snail and more $\mathrm{H} 520^{\text {OV-Snail }}$ migrated across the Matrigel layer compared with their control cells $\left(\mathrm{H} 520^{\mathrm{OV}-\mathrm{VASH} 2}+\right.$ sh-Snail $: 175.36 \pm 23.47 ; \mathrm{H} 520^{\mathrm{OV}-\mathrm{VASH} 2}$ : $254.17 \pm 30.78$; H5 $20^{\mathrm{CTRL}}: 164.24 \pm 20.14, \mathrm{P}=0.024$, Figure $4 D ; 217.93 \pm 16.77$ vs. $125.69 \pm 15.13, \mathrm{P}=0.002$, Figure 4E). Similar results were detected in wound healing assay $\left(\mathrm{H} 520^{\mathrm{OV}-\mathrm{VASH} 2+\text { sh-Snail }}: 41.36 \% \pm 5.69 \% ; \mathrm{H} 520^{\mathrm{OV}-\mathrm{VASH} 2}\right.$ : $69.64 \% \pm 7.15 \% ; \mathrm{H} 520^{\mathrm{CTRL}}: 37.25 \% \pm 4.95 \%, \mathrm{P}=0.005$, Figure $4 F ; 85.32 \% \pm 8.47 \%$ vs. $34.25 \% \pm 5.68 \%, \mathrm{P}=0.001$, Figure $4 G$ ). These results demonstrated that VASH2 promoted the proliferation and invasion of LUSC cells via up-regulating Snail transcription and expression.

\section{Snail regulated VASH2-related lymphangiogenesis via stimulating VEGF-D production in LUSC cells}

The results showed that VEGF-D was also up-regulated 

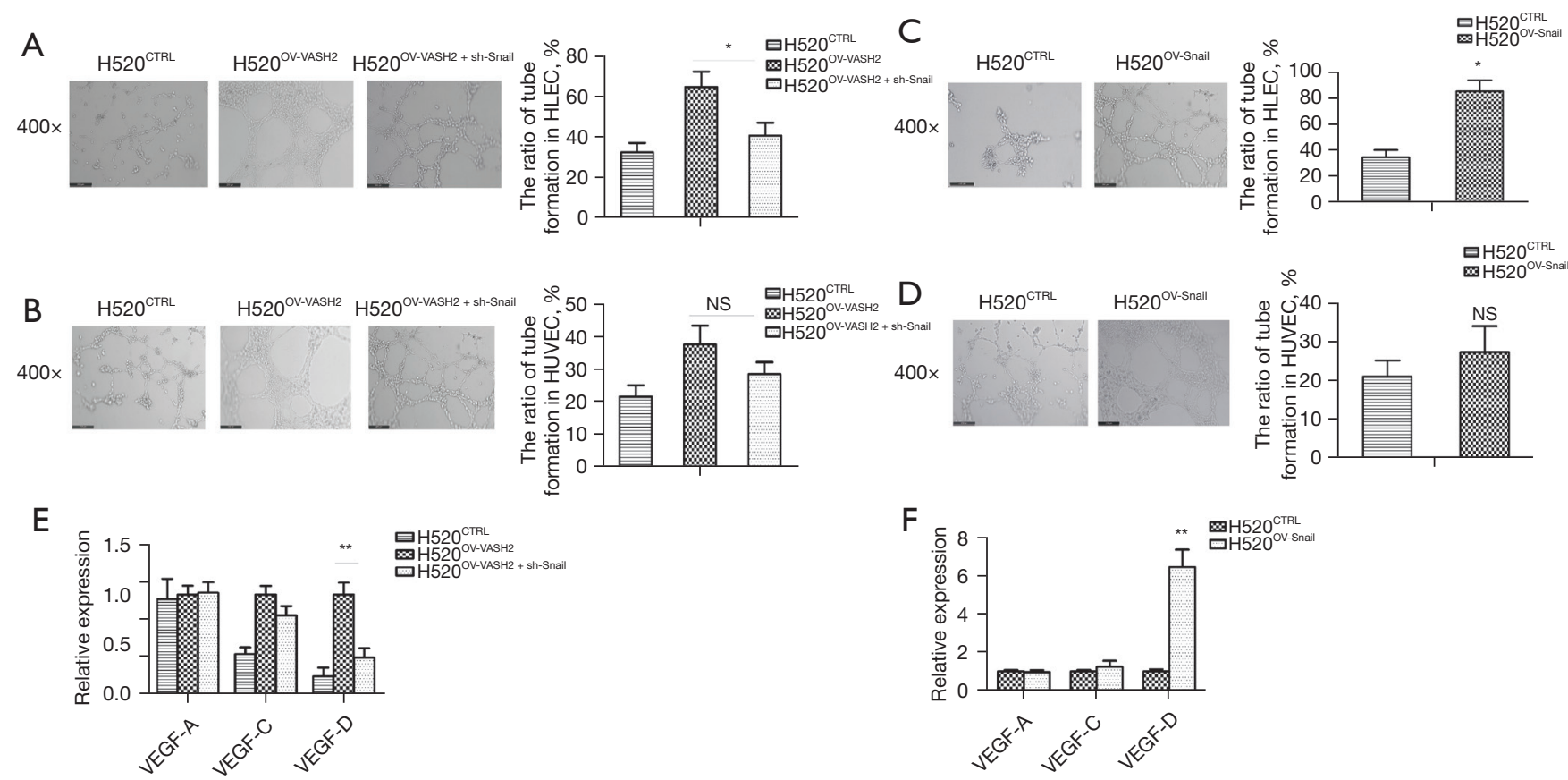

Figure 5 Snail regulated VASH2-related lymphangiogenesis via stimulating VEGF-D production in LUSC cells. (A-D) We transfected $\mathrm{H} 520^{\text {OV-VASH2 }}$ cells with sh-Snail recombinant lentivirus and compared the tube formation capacity of HLECs or HUVECs co-cultured with either H520 ${ }^{\mathrm{CTRL}}$, H520 ${ }^{\text {OV-VASH2 }}$, H520 ${ }^{\text {OV-VASH2 + sh-Snail }}$, or H520 OV-Snail cells. (E,F) To determine if Snail regulated VASH2-stimulated VEGF-D

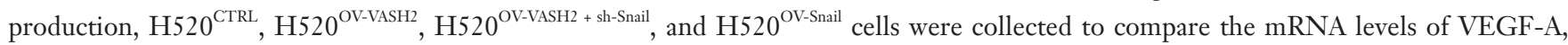
VEGF-C, and VEGF-D by qPCR assay. Scale bar: $200 \mu \mathrm{m}$. *, $\mathrm{P}<0.05$ and **, $\mathrm{P}<0.01$ between the groups, respectively. HLECs, human lymphatic endothelial cells; HUVECs, human umbilical vein endothelial cells; LUSC, lung squamous cell carcinoma; VASH2, vasohibin 2; VEGF, vascular endothelial growth factor; NS, no significance.

in samples with a high expression of Snail in H520 OV-VASH2, which implied a potential causal relationship between Snail and VEGF-D. Therefore, we first determined if Snail mediated VASH2-induced lymphangiogenesis, by transfecting $\mathrm{H} 520^{\text {OV-VASH2 }}$ cells with sh-Snail recombinant lentivirus and comparing the tube formation capacity of HLECs or HUVECs co-cultured with either H520 CTRL, $\mathrm{H} 520^{\text {OV-VASH2 }}$, H520 $0^{\text {OV-VASH2 }+ \text { sh-Snail }}$ or H520 $0^{\text {OV-Snail }}$ cells. The results showed that although the number of HLECformed tubes in the $\mathrm{H} 520^{\mathrm{OV}-\mathrm{VASH} 2}+$ sh-Snail group was less than that in the H520 $0^{\text {OV-VASH2 }}$ group $(40.67 \% \pm 6.43 \%$ vs. $64.67 \% \pm 7.67 \%, \mathrm{P}=0.014$, Figure $5 A$ ), there was no difference between the number of HUVEC-formed tubes in $\mathrm{H} 520^{\text {OV-VASH2 }}$ and H520 ${ }^{\text {OV-VASH2 + sh-Snail }}$ groups $(28.54 \% \pm 3.64 \%$ vs. $37.64 \% \pm 5.79 \%, \mathrm{P}=0.083$, Figure $5 B$ ). Furthermore, when we transfected H520 cells with Snail recombinant lentivirus, the number of HLEC-formed tubes in the $\mathrm{H} 520^{\text {OV-Snail }}$ group was higher than that in the H520 ${ }^{\mathrm{CTRL}}$ group $(85.32 \% \pm 8.47 \%$ vs. $34.25 \% \pm 5.68 \%, \mathrm{P}=0.001$, Figure $5 \mathrm{C}$ ), but there was still no difference in the HUVEC-formed tubes $(20.98 \% \pm 4.23 \%$ vs. $27.36 \% \pm 6.71 \%, \mathrm{P}=0.24$, Figure 5D).

To determine if Snail regulated VASH2-stimulated VEGF-D production, H $520^{\mathrm{CTRL}}$, H $520^{\mathrm{OV}-\mathrm{VASH} 2}$, $\mathrm{H} 520^{\text {OV-VASH2 }}+$ sh-Snail , and H520 ${ }^{\text {OV-Snail }}$ cells were collected to compare the mRNA levels of VEGF-A, VEGF-C, and VEGF-D by qPCR assay. Compared to $\mathrm{H} 520^{\mathrm{OV}-\mathrm{VASH}}$, a significant decrease in the mRNA level of VEGF-D in $\mathrm{H} 520^{\text {OV-VASH } 2 \text { sh-Snail }}$ was seen but no difference was detected in the mRNA levels of VEGF-A and VEGF-C (Figure 5E). Compared to H520 CTRL, over-expression of Snail consistently induced a significant increase of VEGF-D at 6.47-fold, rather than VEGF-A and VEGF-C $(\mathrm{P}=0.008$, Figure $5 F$ ). These results indicated that Snail regulated VASH2-related lymphangiogenesis rather than angiogenesis via stimulating VEGF-D production.

\section{VASH2 significantly correlated with either Snail or VEGF-D in primary LUSC tissue}

The protein levels of Snail and VEGF-D in 64 cases of 
primary LUSC tissues were assessed using IHC staining assay (Figure 6A). We used qPCR to detect the mRNA levels of VASH2, Snail, and VEGF-D in LUSC, and found Snail and VEGF-D were highly expressed in VASH2 overexpression samples, and VEGF-D was also highly expressed in Snail overexpression samples (Figure 6B). In addition, the results of IHC were consistent with this result. The proportion of Snail in VASH2-positive LUSC tissues were higher than that in VASH2-negative LUSC tissues $(73.92 \% \pm 2.43 \%$ vs. $20.16 \% \pm 2.72 \%, \mathrm{P}=0.019$, Figure $6 \mathrm{C}$ ), and similar results were observed in the average PR of VEGF-D $(67.06 \% \pm 3.85 \%$ vs. $25.08 \% \pm 3.36 \%$, $\mathrm{P}=0.035$, Figure 6C). Among Snail-positive LUSC patients, the average PR of VEGF-D was much higher than that in Snail-negative LUSC patients $(61.74 \% \pm 4.19 \%$ vs. $20.98 \% \pm 2.87 \%, \mathrm{P}=0.033$, Figure $6 C$ ).

To further compare the correlation among VAHS2/ Snail/VEGF-D and the prognosis of patients with LUSC, we divided them into double positive groups. We compared the OS between VASH2 ${ }^{+}$Snail $^{+}$LUSC patients and non-VASH2 ${ }^{+}$Snail ${ }^{+}$patients, as well as between $\mathrm{VASH}_{2}{ }^{+} \mathrm{VEGF}^{-\mathrm{D}^{+}}$patients and non-VASH $2^{+} \mathrm{VEGF}^{-\mathrm{D}^{+}}$ patients. Kaplan-Meier survival analysis revealed that $\mathrm{VASH}^{+}{ }^{+}$Snail ${ }^{+}$patients suffered from shorter OS than nonVASH $2^{+}$Snail ${ }^{+}$patients $(17.21 \pm 1.39$ vs. $70.75 \pm 2.54$ months, $\mathrm{P}=0.006$, Figure $6 D$ ), and VASH $2^{+} \mathrm{VEGF}^{-\mathrm{D}^{+}}$patients exhibited a shorter OS than non-VASH $2^{+} \mathrm{VEGF}^{-\mathrm{D}^{+}}$ patients $(39.93 \pm 5.46$ vs. $63.71 \pm 3.27$ months, $\mathrm{P}=0.017$, Figure 6D).

\section{VASH2 blocking antibody inbibited tumor growth and lymphangiogenesis by attenuating VEGF-D production}

$\mathrm{H} 520^{\mathrm{CTRL}}$ and $\mathrm{H} 520^{\mathrm{OV}-\mathrm{VASH} 2}$ were injected at $1 \times 10^{6}$ tumor cells $/ 100 \mu \mathrm{L}$ per mouse subcutaneously into NOD-SCID mice, and after 26 days, the average volumes of tumors generated in the $\mathrm{H} 520^{\mathrm{OV}-\mathrm{VASH} 2}$ group were nearly three-fold larger than those in the H520 ${ }^{\mathrm{CTRL}}$ group $(1,805.62 \pm 171.56$ vs. $648.64 \pm 92.21 \mathrm{~mm}^{3}, \mathrm{P}=0.041$, Figure $7 A$ ). The proportion of LYVE-1 positive cells referring to lymphoepithelial cells in $\mathrm{H} 520^{\text {OV-VASH2 }}$ was significantly higher than $\mathrm{H} 520^{\mathrm{CTRL}}$ $(75.37 \% \pm 8.63 \%$ vs. $4.26 \% \pm 0.74 \%, \mathrm{P}=0.001$, Figure $7 B)$, which indicated that VASH2 promoted lymphangiogenesis in vivo.

To confirm if targeted therapy against either VASH2 or VEGF-D was efficient to inhibit tumor metastasis and local lymphangiogenesis in vivo, mice were treated with anti-VASH2 or anti-VEGF-D antibodies at a dose of $2.5 \mathrm{mg} / \mathrm{kg}$ bodyweight by i.p. injection three times per week. We found the tumor sizes were significantly reduced after either treatment $\left(\mathrm{H} 520^{\text {OV-VASH2 }}: 1,805.62 \pm 171.56 \mathrm{~mm}^{3}\right.$; $\mathrm{H} 520^{\mathrm{OV}-\mathrm{VASH}} 2+\mathrm{VASH} 2 \mathrm{AB}: 1,105.36 \pm 92.21 \mathrm{~m} \mathrm{~m}^{3}$; H5 $20^{\text {OV-VASH } 2+V E G F-D A B}: 1,281.36 \pm 215.36 \mathrm{~mm}^{3}, \mathrm{P}<0.01$, Figure $7 A$ ). Furthermore, after anti-VASH2 or antiVEGF-D antibodies, the proportion of lymphatic endothelial cells was significantly reduced by more than two times $\left(\mathrm{H} 520^{\mathrm{OV}^{-V A S H}}\right.$ : $75.37 \% \pm 8.63 \%$; H5 $520^{\text {OV-VASH2 }+ \text { VASH2AB }}: 31.86 \% \pm 4.14 \% ;$ H $520^{\text {OV-VASH } 2+\text { VEGF-DAB }}$ : $26.73 \% \pm 3.27 \%, \mathrm{P}<0.01$, Figure $7 B)$. Similar results were observed by flow cytometry by labeling D2-40 positive cells, which is another marker of lymphoepithelial cells (H520 $0^{\text {OV-VASH2 }}: 79.71 \% \pm 9.58 \% ;$ H520 ${ }^{\text {CTRL }}: 32.48 \% \pm 4.36 \%$; H520 $0^{\text {VASH2-VASH2Ab }}: 44.82 \% \pm 5.36 \%$; H520 20 OV-VASH2 + VEGF-DAB $47.42 \% \pm 5.69 \%, \mathrm{P}<0.01$, Figure 7 C).

We then extracted tumor RNA and compared the mRNA levels of Snail and VEGF-D between different groups using qPCR assay. We noticed that the mRNA levels of these genes were significantly up-regulated in $\mathrm{H} 520^{\text {OV-VASH2 }}$ compared to $\mathrm{H} 520^{\mathrm{CTRL}}$, which was consistent with the observation in vitro (Snail: $2.89 \pm 0.36, \mathrm{P}=0.009$; VEGF-D: $4.97 \pm 0.68, \mathrm{P}=0.007$, Figure $7 D, 7 E)$. We also noticed that the mRNA levels of Snail and VEGF-D were significantly down-regulated in $\mathrm{H} 520^{\mathrm{OV}-\mathrm{VASH} 2}+\mathrm{VASH} 2 \mathrm{AB}$ compared to $\mathrm{H} 520^{\mathrm{OV}-\mathrm{VASH} 2}$ (Snail: $0.79 \pm 0.11$ vs. $2.89 \pm 0.36$, $\mathrm{P}=0.006$; VEGF-D: $1.75 \pm 0.84$ vs. $4.97 \pm 0.68, \mathrm{P}=0.006$, Figure $7 D, 7 E$ ) but there was no difference in the mRNA expression of Snail in H520 ${ }^{\text {OV-VASH2 }+ \text { VEGF-DAB }}$ compared with $\mathrm{H} 520^{\text {OV-VASH2 }}$ (Snail: $2.48 \pm 0.19$ vs. $2.89 \pm 0.36$, $\mathrm{P}=0.15$; VEGF-D: $2.12 \pm 0.98 v s .4 .97 \pm 0.68, \mathrm{P}=0.014$, Figure $7 D, 7 E$ ). The same conclusion could be reached by detecting protein level by Western blot, which saw the protein levels of Snail and VEGF-D in H520 ${ }^{\mathrm{OV}-\mathrm{VASH} 2}$ higher than that in $\mathrm{H} 520^{\mathrm{CTRL}}$ (Snail: $1.84 \pm 0.49 \mathrm{vs}$. $1.13 \pm 0.095, \mathrm{P}=0.044$; VEGF-D: $1.49 \pm 0.64$ vs. $0.92 \pm 0.12$, $\mathrm{P}=0.026$, Figure $7 D, 7 E$ ). The protein levels of Snail and VEGF-D were also significantly decreased by adding VASH2 antibody (Snail: $0.57 \pm 0.094$ vs. $1.84 \pm 0.49$, $\mathrm{P}=0.012$; VEGF-D: $0.89 \pm 0.084$ vs. $1.49 \pm 0.64, \mathrm{P}=0.017$, Figure $7 D, 7 E)$, but the addition of VEGF-D antibody produced no difference in the protein level of Snail (Snail: $1.52 \pm 0.28$ vs. $1.84 \pm 0.49, \mathrm{P}=0.38$; VEGF-D: $0.78 \pm 0.19 v s$. 

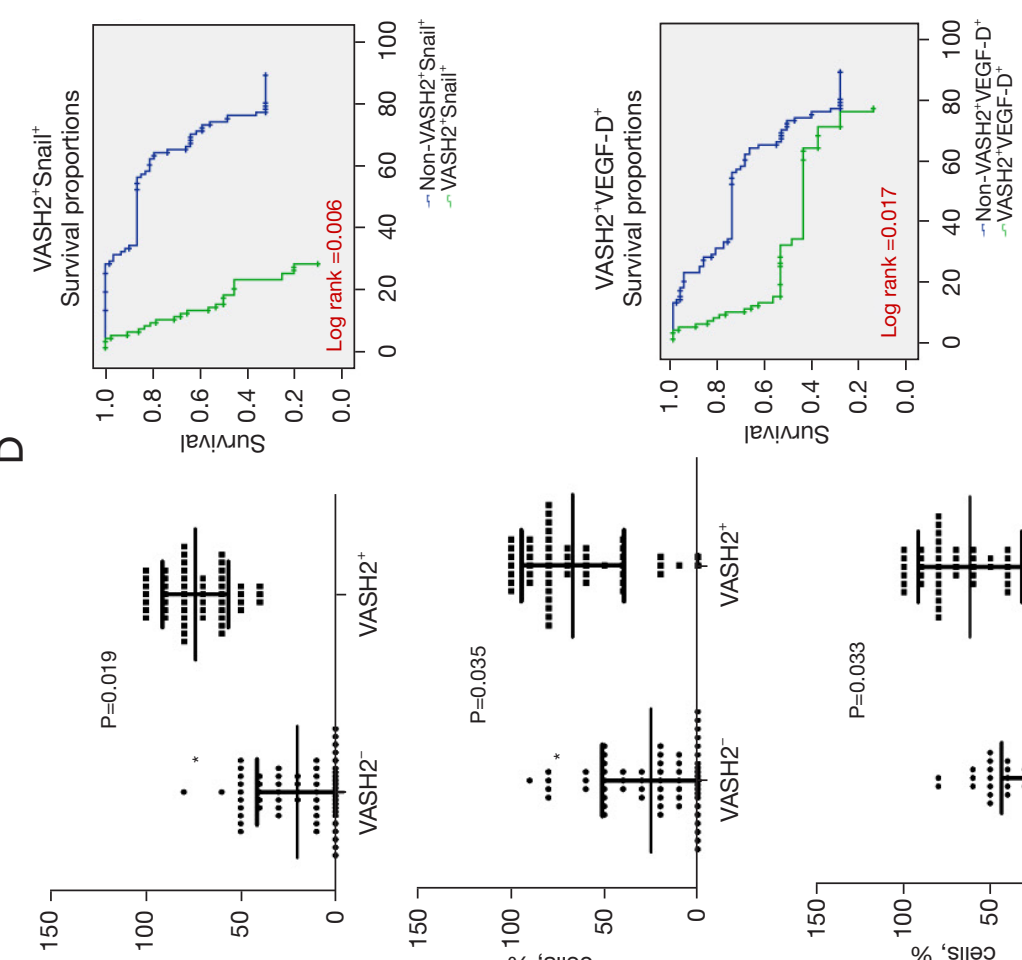

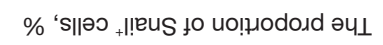

$u$
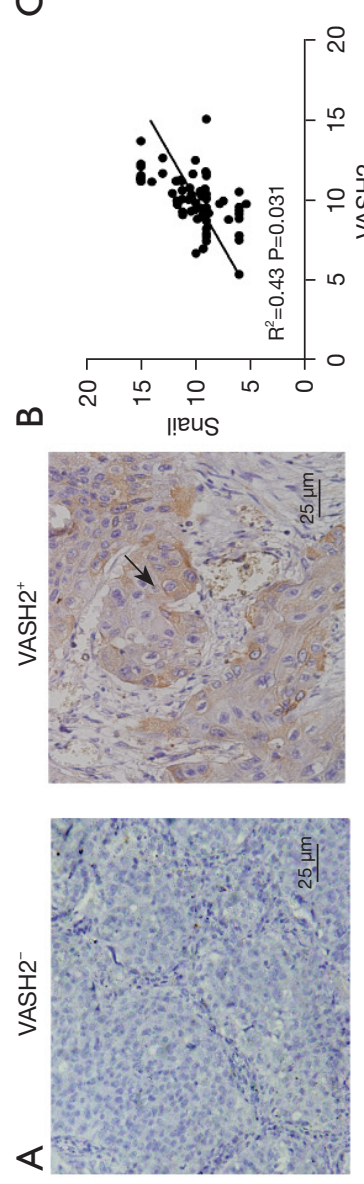

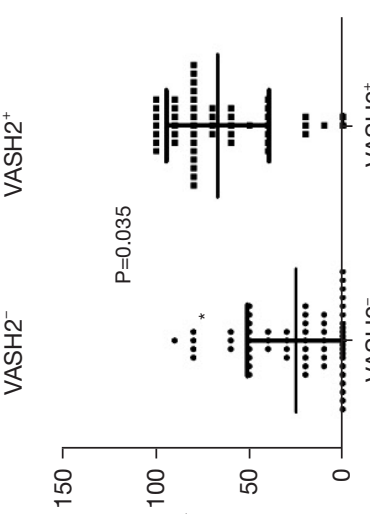

\%

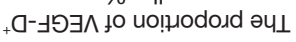
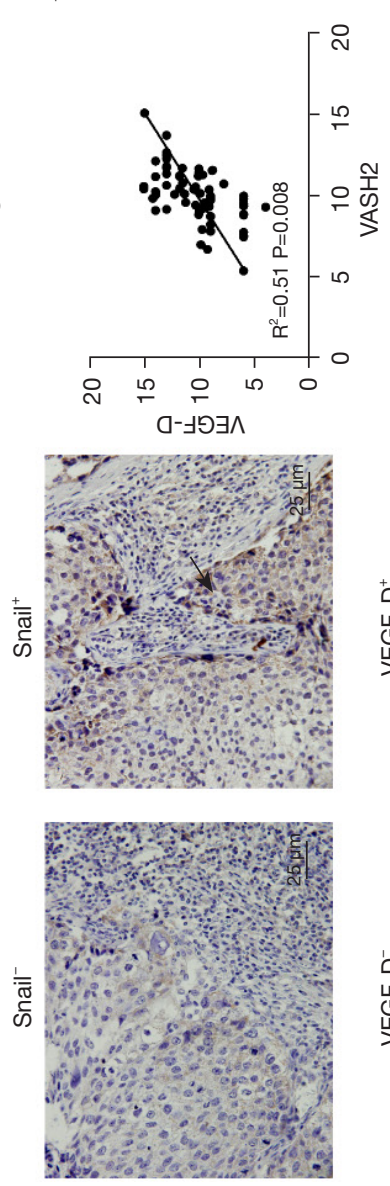

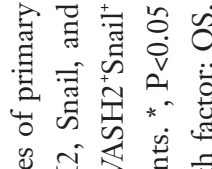

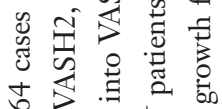

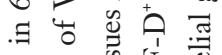

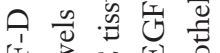

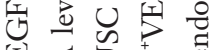

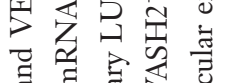

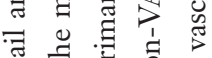

की

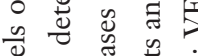

\& 8 苟

.

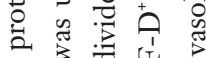

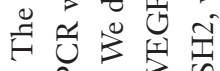

这完空

ن்

क्ष

: :

员药

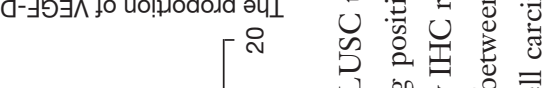



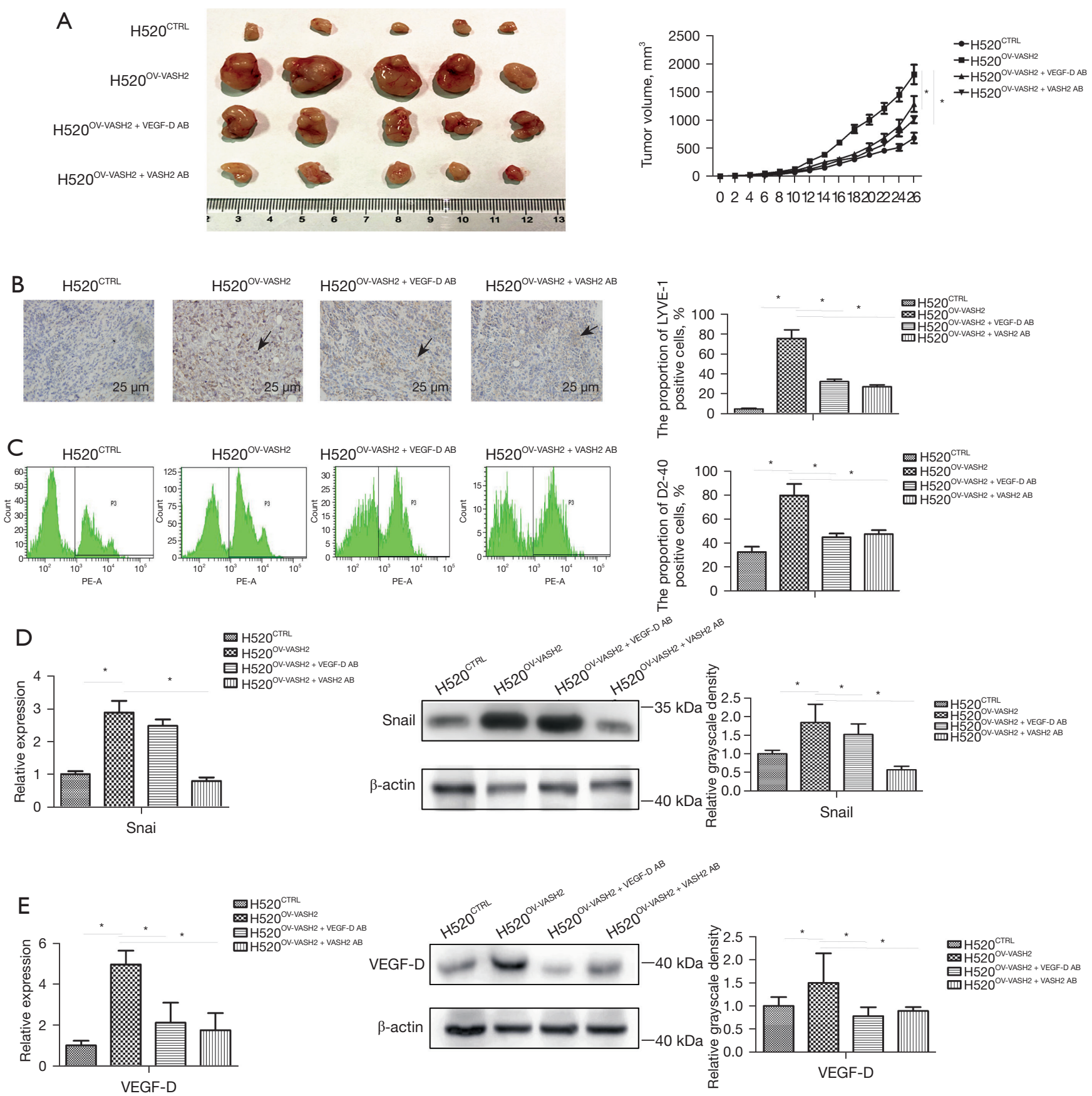

Figure 7 VASH2 blocking antibody inhibited tumor growth and lymphangiogenesis by attenuating VEGF-D production. (A) H520 CTRL and $\mathrm{H} 520^{\mathrm{OV}-\mathrm{VASH} 2}$ were injected at $1 \times 10^{6}$ tumor cells/100 $\mu \mathrm{L}$ per mouse subcutaneously into NOD-SCID mice. Once palpable tumors were formed (in 7-10 days) treatment cycles were initiated. Mice were anesthetized by intraperitoneal injection of $100 \mathrm{mg} / \mathrm{kg}$ anti-VEGF-D and $10 \mathrm{mg} / \mathrm{kg}$ anti-VASH2, then randomly divided into a control, anti-VEGF-D, and anti-VASH2 group, with each containing five mice. Tumor sizes were monitored every 3 days. (B) Tumors were fixed and processed for IHC of the proportion of LYVE-1. The arrow indicates the viewing position. (C) Flow cytometry was used to detect the influence of VASH2 and VEGF-D on lymphoepithelial cells by labeling D240 positive cells. (D,E) mRNA and protein levels of Snail and VEGF-D were compared between different groups using qPCR and Western blot assay. *, $\mathrm{P}<0.05$ between the groups, respectively. IHC, immunohistochemical; VASH2, vasohibin 2; VEGF, vascular endothelial growth factor; LYVE-1, lymphatic vessel endothelial hyaluronic acid receptor-1. 
$1.49 \pm 0.64, \mathrm{P}=0.013$, Figure $7 D, 7 E)$.

\section{Discussion}

Although many studies have confirmed the predominant role of microvascular development, especially angiogenesis, in tumor growth and metastasis, anti-angiogenesis therapy has not achieved sufficient clinical efficacy as expected until now (34). Recent studies have shown that the initial metastasis of most malignant tumors is not through blood vessels, but firstly through lymphatic vessels to local lymph nodes $(35,36)$. As lymphangiogenesis, the development of new lymph vessels, has been reported to promote lymphatic invasion and lymph node metastasis, antilymphangiogenesis therapy has become a relatively hot topic of clinical investigation and might be a promising strategy to inhibit the metastasis and spread of tumors in the early stage. Lymph node metastasis is a prognostic indicator for systemic tumor spread in many types of cancers, and tumor lymphangiogenesis correlates with reduced survival. Tumor lymphangiogenesis occurs both in primary tumors and at distant (pre-) metastatic sites, and facilitates lymphatic invasion and tumor cell dissemination (37). Although lymphangiogenesis and lymphatic metastasis play an important role in tumor malignant progression, there are very few studies on the mechanism of lymphatic metastasis in LUSC. Like in other tumors, VEGF-C and VEGF-D are the most potent lymphatic endothelial cell forming factors, which promote the formation of VEGFR3 positive lymphatic vessels in the stroma as the most important pathway in lymphangiogenesis (38). In addition, there are reports in the latest literature, Inflammatory factors cyclooxygenase 2 (COX 2), interleukin (IL)-7, lymphangiogenic factors, including fibroblast growth factor (FGF) (22,23), epidermal 1 growth factor (EGF), ANGPT2, FGF-2 and platelet-derived growth factor BB (PDGF$\mathrm{BB})$ and chemokine CCL21 can also promote lymphatic metastasis. However, there are very few studies on the mechanism of lymphatic metastasis in LUSC (24).

In this study, based on 937 LUSC gene expression profiling data from 11 public datasets in the GEO and TCGA datasets, as well as 64 LUSC primary tissues from a TJMUCH independent cohort, we demonstrated that VASH2 was an independent prognostic biomarker for LUSC. We validated the positive correlation between VASH2 and poor prognosis of LUSC patients both at mRNA and protein levels. The IHC results of an independent Chinese LUSC cohort showed there was no correlation between the expression of VASH2 and CD31 and other vascular endothelial markers, while pathological analysis showed that the expression of VASH2 was significantly related to the number of lymph node metastasis in LUSC patients. Furthermore, we found that VASH2 expression was significantly positively correlated with the number of lymph node metastasis rather than distant metastasis. We showed that VASH2 promoted amplification and tube-formation of HUVEC and HLEC cells and accelerated the proliferation and invasion of LUSC cells. Further studies demonstrated that VASH2 facilitated lymphangiogenesis via up-regulating VEGF-D production in LUSC cells and enhanced tumor proliferation and invasion via up-regulating Snail expression.

VASH2 has been reported as an angiogenic factor which promotes tumor development and progression $(13,25)$, regulate the expression of VEGF through autocrine and paracrine mechanisms, and promotes angiogenesis (26). The VEGF family was identified as an endothelial cellspecific mitogen having the capacity to induce physiological and pathological angiogenesis and lymphangiogenesis, and among its members, VEGF-C and VEGF-D have similar structures but bind and activate VEGF receptor VEGFR-2 and VEGFR-3, respectively. VEGF-C and VEGF-D promoted angiogenesis and lymphangiogenesis within and at the periphery of solid tumors, as well as enhancing solid tumor growth and metastatic spread to lymph nodes and distant organs $(27,28)$. Although an understanding of the molecular mechanisms of VEGF-C in lymphatic development and lymphangiogenesis has been greatly appreciated in multiple cancers, the role of VEGF-D is less well understood. Previous studies showed that VEGF-D could compensate for the loss of VEGF-C for the sprouting of lymphatics, indicating VEGF-D might play a more subtle role in regulating lymphatic vascular development than VEGF-C (29-31). In this study, we found VEGF-D was significantly up-regulated in $\mathrm{H} 520^{\mathrm{OV}-\mathrm{VASH} 2}$ cells, but the expression of VEGF-C did not change significantly, suggesting that VASH2 promoted lymphangiogenesis mainly through up-regulation of VEGF-D, but not VEGF-C signaling.

Snail is a TF involved in EMT, but also plays an important role in lymphatic metastasis and increased lymph node metastasis (32) . Consistently, we found that Snail positively correlated with the level of VASH2 and the status of lymph node metastasis, although the relationship between Snail and lymphangiogenesis, as well as Snail and VEGF-D, are not yet fully investigated (33). 
In this study, we found that Snail participated in VASH2-mediated lymphangiogenesis via up-regulation of VEGF-D in LUSC cells. Inhibition of VEGF-D via antiVEGF-D antibody could reduce tumor growth in vivo, not affecting Snail expression, which implied a "VASH2Snail-VEGF-D" axis in promoting lymphangiogenesis and tumor progression in LUSC. Furthermore, we observed that inhibition of VASH2 had a better therapy effect than inhibition of VEGF-D in a mouse model, which is most likely due to the function of VASH2 monoclonal antibodies in interfering with the proliferation of cancer cells, as well as lymphangiogenesis, in tumor tissues simultaneously.

Increasing evidences indicate that the degree of malignancy of cancers is determined not only by the intrinsic features of the tumor cells, but also by components in the tumor microenvironment (TME), including immune cells, mesenchymal cells, endothelial cells, inflammatory mediators, and extracellular matrix molecules (39). Tumorinfiltrating immune cells (TIICs) and stromal cells, which are two major types of non-tumor cell components, have been proposed to be valuable for the diagnostic and prognostic assessment of tumors $(40,41)$. LUSC and LUAD, which are the two major subtypes of lung cancer, have shown significant differences in genomic and histological heterogeneities. LUSC has low sensitivity to chemotherapy, in which lack of actionable mutations and frequent immune evasion limited the benefit from target therapy and immune monotherapy. And the prognostic significance of various immune components from LUSC and LUAD were differential or even opposite $(42,43)$. It is worthy to further investigate the roles of VASH2 in regulating LUSC TME in the future. Compared with LUAD, LUSC is associated with the more proximal airways, which usually has a stronger correlation with smoking and inflammatory diseases (6). LUSC has low sensitivity to chemotherapy, in which lack of actionable mutations and frequent immune evasion limited the benefit from target therapy and immune monotherapy $(7,8)$.

In conclusion, we found that a high expression of VASH2 was significantly related to poor prognosis and lymph node metastasis in LUSC patients. VASH2 could increase the expression of VEGF-D, up-regulate the expression of Snail, down-regulate the expression of E-cadherin in LUSC cells, and promote the formation of lymphatics. Therefore, further investigation to obtain a comprehensive understanding of VASH2 in tumor development may provide us with more effective therapeutic strategies for treating metastatic disease.

\section{Acknowledgments}

Funding: This work was supported by the National Natural Science Foundation of China (grant No. 82072588, 81872143, 81702280); National Science and Technology support Program of China (grant No. 2018ZX09201015); Projects of Science and Technology of Tianjin (grant No. 18JCQNJC82700); and Key Project of Tianjin Health and Family Planning Commission (grant No. 16KG126).

\section{Footnote}

Reporting Checklist: The authors have completed the ARRIVE reporting checklist. Available at https://atm. amegroups.com/article/view/10.21037/atm-21-4865/rc

Data Sharing Statement: Available at https://atm.amegroups. com/article/view/10.21037/atm-21-4865/dss

Conflicts of Interest: All authors have completed the ICMJE uniform disclosure form (available at https://atm. amegroups.com/article/view/10.21037/atm-21-4865/coif). The authors have no conflicts of interest to declare.

Ethical Statement: The authors are accountable for all aspects of the work in ensuring that questions related to the accuracy or integrity of any part of the work are appropriately investigated and resolved. The study was conducted in accordance with the principles of the Declaration of Helsinki (as revised in 2013). This study was approved by the Ethics Committee of Tianjin Medical University (No. Ek2017055), and written informed consent was obtained from the patients. All procedures involving animals were approved by the Ethics Committee for Animal Experiments at the Tianjin Medical University Cancer Institute and Hospital (No. NSFC-AE-2020101) and in compliance with the Guide for the Care and Use of Laboratory Animals, 8th edition.

Open Access Statement: This is an Open Access article distributed in accordance with the Creative Commons Attribution-NonCommercial-NoDerivs 4.0 International License (CC BY-NC-ND 4.0), which permits the noncommercial replication and distribution of the article with the strict proviso that no changes or edits are made and the original work is properly cited (including links to both the formal publication through the relevant DOI and the license). See: https://creativecommons.org/licenses/by-nc-nd/4.0/. 


\section{References}

1. Rafiemanesh H, Mehtarpour M, Khani F, et al. Epidemiology, incidence and mortality of lung cancer and their relationship with the development index in the world. J Thorac Dis 2016;8:1094-102.

2. Zakaria N, Yusoff NM, Zakaria Z, et al. Human non-small cell lung cancer expresses putative cancer stem cell markers and exhibits the transcriptomic profile of multipotent cells. BMC Cancer 2015;15:84.

3. Jemal A, Siegel R, Ward E, et al. Cancer statistics, 2009. CA Cancer J Clin 2009;59:225-49.

4. Patz EF Jr, Greco E, Gatsonis C, et al. Lung cancer incidence and mortality in National Lung Screening Trial participants who underwent low-dose CT prevalence screening: a retrospective cohort analysis of a randomised, multicentre, diagnostic screening trial. Lancet Oncol 2016;17:590-9.

5. Hu JM, Liu K, Liu JH, et al. The increased number of tumor-associated macrophage is associated with overexpression of VEGF-C, plays an important role in Kazakh ESCC invasion and metastasis. Exp Mol Pathol 2017;102:15-21.

6. Mumprecht V, Detmar M. Lymphangiogenesis and cancer metastasis. J Cell Mol Med 2009;13:1405-16.

7. Li S, Li Q. Cancer stem cells, lymphangiogenesis, and lymphatic metastasis. Cancer Lett 2015;357:438-47.

8. Ikemura S, Aramaki N, Fujii S, et al. Changes in the tumor microenvironment during lymphatic metastasis of lung squamous cell carcinoma. Cancer Sci 2017;108:136-42.

9. Moon Y, Park JK, Lee KY, et al. Lymphatic invasion is a more significant prognostic factor than visceral pleural invasion in non-small cell lung cancer with tumours of $3 \mathrm{~cm}$ or less. Respirology 2017;22:1179-84.

10. Watabe T. Roles of transcriptional network during the formation of lymphatic vessels. J Biochem 2012;152:213-20.

11. Sato Y. The vasohibin family: a novel family for angiogenesis regulation. J Biochem 2013;153:5-11.

12. Koyanagi T, Suzuki Y, Komori K, et al. Targeting human vasohibin-2 by a neutralizing monoclonal antibody for anti-cancer treatment. Cancer Sci 2017;108:512-9.

13. Kitahara S, Suzuki Y, Morishima M, et al. Vasohibin-2 modulates tumor onset in the gastrointestinal tract by normalizing tumor angiogenesis. Mol Cancer 2014;13:99.

14. Tu M, Lu C, Lv N, et al. Vasohibin 2 promotes human luminal breast cancer angiogenesis in a non-paracrine manner via transcriptional activation of fibroblast growth factor 2. Cancer Lett 2016;383:272-81.
15. Takahashi Y, Koyanagi T, Suzuki Y, et al. Vasohibin-2 expressed in human serous ovarian adenocarcinoma accelerates tumor growth by promoting angiogenesis. Mol Cancer Res 2012;10:1135-46.

16. Kimura H, Miyashita H, Suzuki Y, et al. Distinctive localization and opposed roles of vasohibin-1 and vasohibin-2 in the regulation of angiogenesis. Blood 2009;113:4810-8.

17. Koyanagi T, Saga Y, Takahashi Y, et al. Downregulation of vasohibin-2, a novel angiogenesis regulator, suppresses tumor growth by inhibiting angiogenesis in endometrial cancer cells. Oncol Lett 2013;5:1058-62.

18. Heishi T, Hosaka T, Suzuki Y, et al. Endogenous angiogenesis inhibitor vasohibin1 exhibits broad-spectrum antilymphangiogenic activity and suppresses lymph node metastasis. Am J Pathol 2010;176:1950-8.

19. Zhang Y, Xue X, Zhao X, et al. Vasohibin 2 promotes malignant behaviors of pancreatic cancer cells by inducing epithelial-mesenchymal transition via Hedgehog signaling pathway. Cancer Med 2018;7:5567-76.

20. Xue X, Zhang Y, Zhi Q, et al. MiR200-upregulated Vasohibin 2 promotes the malignant transformation of tumors by inducing epithelial-mesenchymal transition in hepatocellular carcinoma. Cell Commun Signal 2014;12:62.

21. Worlein JM, Baker K, Bloomsmith M, et al. The Eighth Edition of the Guide for the Care And Use Of Laboratory Animals (2011); Implications for Behavioral Management. Am J Primatol 2011;73:98.

22. Shin JW, Min M, Larrieu-Lahargue F, et al. Prox1 promotes lineage-specific expression of fibroblast growth factor (FGF) receptor-3 in lymphatic endothelium: a role for FGF signaling in lymphangiogenesis. Mol Biol Cell 2006;17:576-84.

23. Cao R, Ji H, Feng N, et al. Collaborative interplay between FGF-2 and VEGF-C promotes lymphangiogenesis and metastasis. Proc Natl Acad Sci U S A 2012;109:15894-9.

24. Dong Z, Xu QH, Zhu YB, et al. Investigation of Targeting Relationship between Micro-Rna-22 and Vegfr3 in Lung Squamous Cell Carcinoma. Comb Chem High Throughput Screen 2021;24:148-54.

25. Norita R, Suzuki Y, Furutani Y, et al. Vasohibin-2 is required for epithelial-mesenchymal transition of ovarian cancer cells by modulating transforming growth factor- $\beta$ signaling. Cancer Sci 2017;108:419-26.

26. Xue X, Gao W, Sun B, et al. Vasohibin 2 is transcriptionally activated and promotes angiogenesis in hepatocellular carcinoma. Oncogene 2013;32:1724-34. 
27. Choi JU, Chung SW, Al-Hilal TA, et al. A heparin conjugate, LHbisD4, inhibits lymphangiogenesis and attenuates lymph node metastasis by blocking VEGF-C signaling pathway. Biomaterials 2017;139:56-66.

28. Alishekevitz D, Gingis-Velitski S, Kaidar-Person O, et al. Macrophage-Induced Lymphangiogenesis and Metastasis following Paclitaxel Chemotherapy Is Regulated by VEGFR3. Cell Rep 2016;17:1344-56.

29. Miyata Y, Matsuo T, Ohba K, et al. 1135 Cigarette smoking induces lymphangiogenesis, but not angiogenesis, and vascular endothelial growth factor-D, but not -A or -C in human bladder cancer tissues. Journal of Urology 2013;189:e463.

30. Lin W, Jiang L, Chen Y, et al. Vascular endothelial growth factor-D promotes growth, lymphangiogenesis and lymphatic metastasis in gallbladder cancer. Cancer Lett 2012;314:127-36.

31. Ebata R, Abe J, Yasukawa K, et al. Increased production of vascular endothelial growth factor-d and lymphangiogenesis in acute Kawasaki disease. Circ J 2011;75:1455-62.

32. Cho YA, Kim EK, Cho BC, et al. Twist and Snail/Slug Expression in Oropharyngeal Squamous Cell Carcinoma in Correlation With Lymph Node Metastasis. Anticancer Res 2019;39:6307-16.

33. Harris K, Gelberg HB, Kiupel M, et al. Immunohistochemical Features of Epithelial-Mesenchymal Transition in Feline Oral Squamous Cell Carcinoma. Vet Pathol 2019;56:826-39.

34. Yi M, Jiao D, Qin S, et al. Synergistic effect of immune checkpoint blockade and anti-angiogenesis in cancer treatment. Mol Cancer 2019;18:60.

35. Pereira ER, Kedrin D, Seano G, et al. Lymph node metastases can invade local blood vessels, exit the node, and colonize distant organs in mice. Science 2018;359:1403-7.

36. Stewart CL, Warner S, Ito K, et al. Cytoreduction for colorectal metastases: liver, lung, peritoneum, lymph nodes, bone, brain. When does it palliate, prolong survival, and potentially cure? Curr Probl Surg 2018;55:330-79.

37. Stacker SA, Williams SP, Karnezis T, et al. Lymphangiogenesis and lymphatic vessel remodelling in cancer. Nat Rev Cancer 2014;14:159-72.

38. Karroum A, Mirshahi P, Faussat AM, et al. Tubular network formation by adriamycin-resistant MCF-7 breast cancer cells is closely linked to MMP-9 and VEGFR-2/VEGFR-3 over-expressions. Eur J Pharmacol 2012;685:1-7.

39. Hanahan D, Coussens LM. Accessories to the crime: functions of cells recruited to the tumor microenvironment. Cancer Cell 2012;21:309-22.

40. Gregório AC, Lacerda M, Figueiredo P, et al. Therapeutic Implications of the Molecular and Immune Landscape of Triple-Negative Breast Cancer. Pathol Oncol Res 2018;24:701-16.

41. Mlecnik B, Van den Eynde M, Bindea G, et al. Comprehensive Intrametastatic Immune Quantification and Major Impact of Immunoscore on Survival. J Natl Cancer Inst 2018.

42. Meng X, Gao Y, Yang L, et al. Immune Microenvironment Differences Between Squamous and Non-squamous Non-small-cell Lung Cancer and Their Influence on the Prognosis. Clin Lung Cancer 2019;20:48-58.

43. Faruki H, Mayhew GM, Serody JS, et al. Lung Adenocarcinoma and Squamous Cell Carcinoma Gene Expression Subtypes Demonstrate Significant Differences in Tumor Immune Landscape. J Thorac Oncol 2017;12:943-53.

(English Language Editor: B. Draper)
Cite this article as: Liu $\mathrm{P}$, Zhang $\mathrm{R}$, Han L, Zhang $\mathrm{X}$, Ye Y, Yu W, Ren X, Zhang W, Yu J. Vasohibin 2 promotes lymphangiogenesis of lung squamous cell carcinoma through snail-dependent vascular endothelial growth factor-D (VEGF-D) signaling pathway. Ann Transl Med 2022;10(2):39. doi: $10.21037 / \mathrm{atm}-21-4865$ 

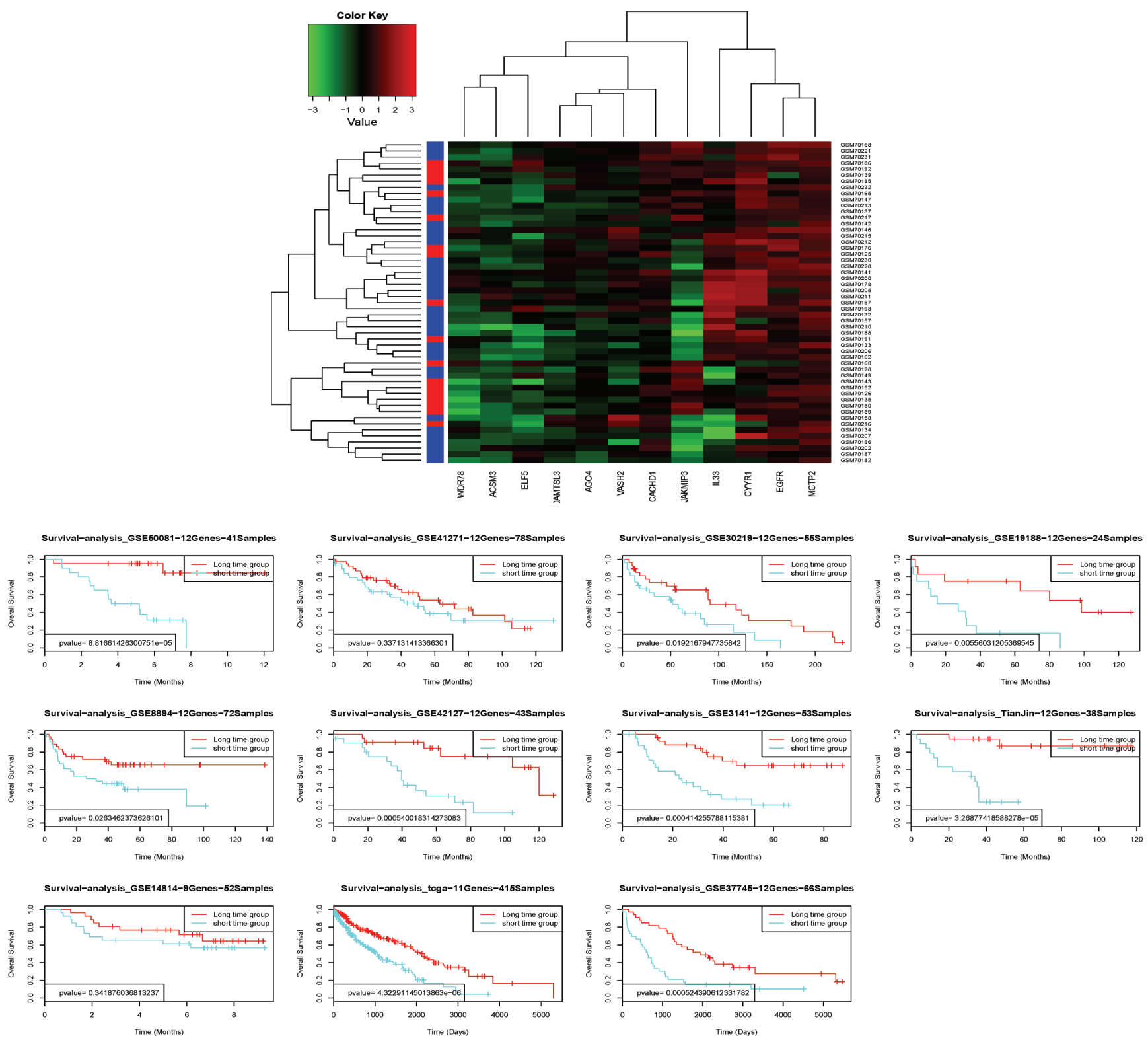

Figure S1 Twelve highly differentially expressed genes significantly correlated with poor prognosis. We collected and analyzed public datasets downloaded from the Gene Expression Omnibus (GEO) database and analyzed the correlation between 12 genes and prognosis in patients with LUSC. LUSC, lung squamous cell carcinoma; GEO, Gene Expression Omnibus. 
A
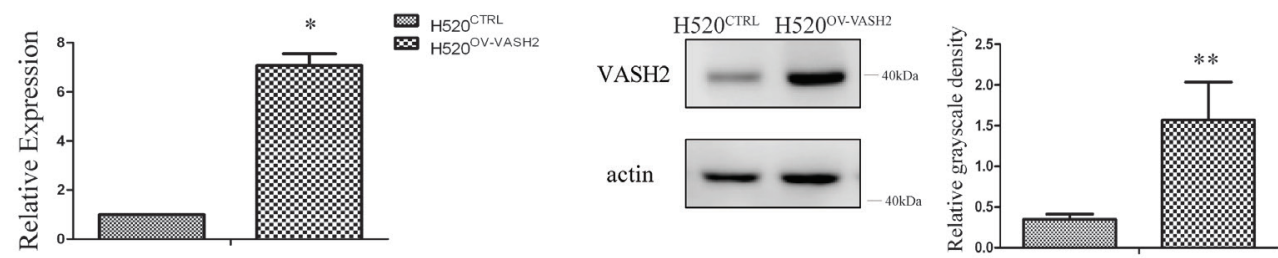

B
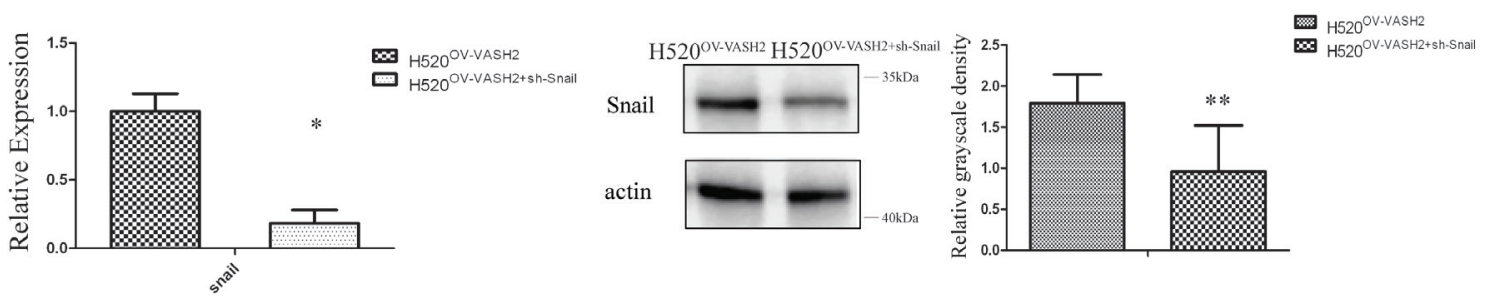

C
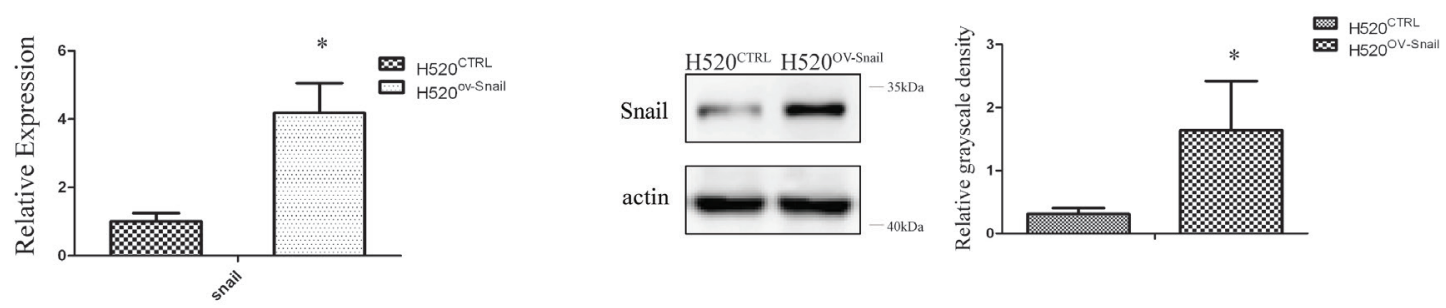

Figure S2 Establishment of H520 $0^{\text {OV-VASH2 }}$, H520 OV-VASH2+sh-Snail , and H520 OV-Snail (A) The establishment of H520 ${ }^{\text {OV-VASH2 }}$ was verified by qPCR

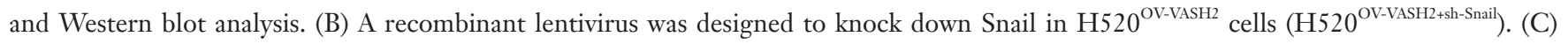
Snail expression in $\mathrm{H}_{52} \mathrm{C}^{\mathrm{CTRL}}$ and $\mathrm{H} 520^{\text {OV-Snail }}$., $\mathrm{P}<0.05$ and ${ }^{* *}, \mathrm{P}<0.01$ between the groups, respectively. VASH2, vasohibin 2.

Table S1 Primer sequencing for RT-qPCR analysis

\begin{tabular}{|c|c|c|c|}
\hline No. & Gene name & Forward primer & Reverse primer \\
\hline 1 & $\beta$-catenin & 5'-TGGTGACAGGGAAGACATCA-3' & 5'-CCATAGTGAAGGCGAACTGC-3' \\
\hline 2 & Twist1 & 5'-АСTTCCTCTACCAGGTCCTCCAG-3' & 5'-ССТССАTССTCCAGACCGAGAA-3' \\
\hline 3 & E-cadherin & 5'-TGAAGGTGACAGAGCCTCTGGAT-3' & 5'-TGGGTGAATTCGGGCTTGTT-3' \\
\hline 4 & $N$-cadherin & 5'-ACAGTGGCCACCTACAAAGG-3' & 5'-CCGAGATGGGGTTGATAATGC-3' \\
\hline 6 & Slug & 5'-TGCCTGTCATACCACAACCAGA-3' & 5'-GGAGGAGGTGTCAGATGGAGGA-3' \\
\hline 7 & Zeb1 & 5'-ACCTGCCAACAGACCAGACAGT-3' & 5'-ACATCCTGCTTCATCTGCCTGAG-3' \\
\hline 8 & Zeb2 & 5'-CAAGGAGCAGGTAATCGCAAGT-3' & 5'-GCAGTTTGGGCACTCGTAAGGTT-3' \\
\hline 9 & VEGF-A & 5'-GGCCAGCACATAGGAGAGAT-3' & 5'-ACACGTCTGCGGATCTTGTA-3' \\
\hline
\end{tabular}

RT-qPCR, real-time quantitative PCR; VEGF, vascular endothelial growth factor. 